\title{
Study on Compound Mode Crack Propagation Law of Semi Circular Arch Roadway Under Impact Load
}

Chengxiao Li ( $\sim$ licx93@163.com )

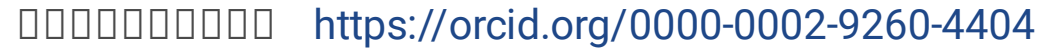

\section{Renshu Yang}

University of Science and Technology Beijing

Yuantong Zhang

China University of Mining and Technology - Beijing Campus

Chen An

China University of Mining and Technology - Beijing Campus

\section{Research}

Keywords: Defect location, Dynamic caustics, SHPB, ABAQUS, Semi-circular arch roadway

Posted Date: February 23rd, 2021

DOl: https://doi.org/10.21203/rs.3.rs-228555/v1

License: (c) (i) This work is licensed under a Creative Commons Attribution 4.0 International License.

Read Full License

Version of Record: A version of this preprint was published at International Journal of Coal Science \& Technology on July 14th, 2021. See the published version at https://doi.org/10.1007/s40789-021-004504. 


\title{
Study on compound mode crack propagation law of semi circular arch roadway under impact load
}

\author{
Chengxiao Li ${ }^{\mathrm{a},}$, , Renshu Yang ${ }^{\mathrm{a}, \mathrm{b}}$, Yuantong Zhang ${ }^{\mathrm{a}}$, Chen $\mathrm{An}^{\mathrm{a}}$
}

\begin{abstract}
Various kinds of defects are usually contained in the underground roadway. When the roadway is impacted by external load, the location of defects will influence the roadway with different degrees. In order to study the effect of the location of defects on crack propagation in roadway, in this paper, the stress wave produced by the bullet impacting the incident rod was used as the impact load. Meanwhile, the variations of speed, displacement and dynamic stress intensity factor (DSIF) of cracks, during crack propagation, were obtained by using the experimental system of digital laser dynamic caustics (DLDC). And the extended finite element software ABAQUS is used for numerical simulation. Based on the method of experimental-numerical simulation, the crack propagation path is verified and the impact fracture behavior of semi-circular arch roadway with different defect positions is presented. It can be concluded that when the prefabricated crack is located at the central axis of sample, the crack propagation belongs to pure mode I; when the prefabricated crack is $5 \mathrm{~mm}$ away from the central axis, the crack propagation appears between mode I and I-II mixed mode alternately; when the prefabricated crack is at the edge of semi-circular arch roadway, the crack propagation follows I-II mixed mode
\end{abstract}

.Keywords Defect location; Dynamic caustics, SHPB, ABAQUS, Semi-circular arch roadway

\section{Introduction}

Due to the increasing consumption of shallow coal in today's social development, the mining of coal resources has gradually shifted to deeper underground. As an important part of coal mining, semi-circular arch roadway surrounding rock defects such as cracks and holes will affect the stability of roadway structure in the process of excavation or structural maintenance. When the surrounding rock with defects is subjected to external dynamic load, such as blasting, roof collapse, rock burst, etc., the shock wave will cause further cracking and expansion of the original defects of the rock mass. It even penetrates with other defects around the rock mass, which will destroy the local stability of the rock mass and, in serious cases, cause the destruction of the roadway. Under the action of impact dynamic load, the crack propagation track, propagation speed and stress intensity in the process of crack propagation will be affected by the crack location. Therefore, it is of great practical significance to study different crack locations for crack propagation process and related parameters in semi-circular arch roadway.

The influence of defects on dynamic fracture of media has always been a hot issue in fracture mechanics research. Yang $\mathrm{RS}^{1}$ studied the influence of different angles of prefabricated crack on crack propagation by using drop hammer to impact medium containing prefabricated crack. Yue $\mathrm{ZW}^{2}$ conducted a three-point bending experiment and studied the crack propagation under impact load when the loading direction and crack angle

\footnotetext{
$\square$ Corresponding author. E-mail: licx93@163.com

a School of Mechanics \& Civil Engineering, China University of Mining \& Technology, Beijing 100083, China

b School of Civil and Resource Engineering, University of Science and Technology Beijing, Beijing 100083, China
} 
of the drop hammer were different. Wang $\mathrm{YB}^{3}$ studied the effect of empty hole on the crack movement of PMMA specimen under impact loading. Li $\mathrm{ZC}^{4}$ studied the influence of fracture dip angle in three-dimensional space on dynamic fracture of rock-like medium. Liu $\mathrm{W}^{5}$ studied the effect of external impact on PMMA specimen multi-crack propagation. Yao $\mathrm{XF}^{6-7}$ studied the interaction and propagation of two parallel precast cracks under dynamic tensile loading.

The development of numerical simulation provides a convenient and effective met-hod for studying the influence of defects on dynamic fracture of media, Especially f-or the prediction of mixed mode crack propagation process. At present, the commonly used numerical simulation methods mainly include finite element method $(\mathrm{FEM})^{8}$, finite difference method $(\mathrm{FDM})^{9}$ 、 extended finite element method (XFEM) ${ }^{10}$ and discrete element method $(\mathrm{DEM})^{11}$ et al. Many scholars have explored the concrete situation of crack propagation in the roadway through numerical simulation and experiment, and have achieved many important results $^{12-19}$. Guo $\mathrm{DM}^{20-21}$ studied the influence of explosion load on crack propagation behavior in roadway, and obtained the evolution law of dynamic stress intensity factor of crack tip by comparing the numerical simulation results. Zhu $\mathrm{ZM}{ }^{22-24}$ carried out the test of rock tunnel under heavy hammer impact, and studied the variation of crack propagation velocity, path and other parameters in the tunnel by using numerical simulation and strain gauge method. However, the methods used in the above researches are usually SHPB combined with numerical simulation, explosion combined with caustics and impact combined with caustics. There are few researches on the dynamic propagation of crack and its process under uniform stress wave by caustic method.

PMMA has good brittle fracture performance under dynamic loading and excellent optical performance. Therefore, it is often used as rock-like materials to study the dynamic fracture process of brittle materials ${ }^{25}$. In this paper, we combine the caustics system (DLDC) with stress wave loading system, and use PMMA as the material medium to study the propagation of prefabricated cracks in different positions under stress wave loading. At the same time, the extended finite element method (EFEM) of commercial software ABAQUS is used to simulate the crack growth process, and the test results are compared with the simulation results.

\section{Test principle and system}

\subsection{Principle of caustics test method}

In 1964, Manogg ${ }^{26}$ first proposed the experimental method of caustics to solve the problem of singularity in the experiment, and used this method to carry out the experiment of crack propagation in a plate with micro holes. It is then extended to dynamic fracture problems under different loads by Theocari ${ }^{27}$ and Kalthoff ${ }^{28}$. Guan $\mathrm{DC}^{29}$ and $\mathrm{Wu} \mathrm{X}{ }^{30}$ first introduced the method of using caustics to study static fracture in China. Yang LY and Yang $\mathrm{RS}^{31}$ developed a new digital laser dynamic caustic experiment system by combining high-speed photography system and laser system. On this basis, the caustics method is widely used in the dynamic fracture process of rocks ${ }^{32-33}$.

The solid model has a uniform thickness before it is deformed. It deforms when subjected to an external load, and the thickness of the region near the internal singularity will 
no longer remain uniform. Because the thickness of the model changes, when parallel light is incident perpendicular to the surface of the specimen, its refractive index will also change. As a result, the reflected light and refracted light on the back surface of the model will no longer be parallel, and a three-dimensional caustic surface will be formed in the air. As shown in figure 1, these reflected and refracted rays are projected on a parallel reference plane within a certain range from the model, and the cross section of the caustic surface will be obtained. The red curves shown in figure 2(a) and figure 2(b) are respectively the caustics diagrams of type I and I-II mixed cracks formed under the reflected tensile stress of the specimen. The black area enclosed in the middle is the caustic spots.

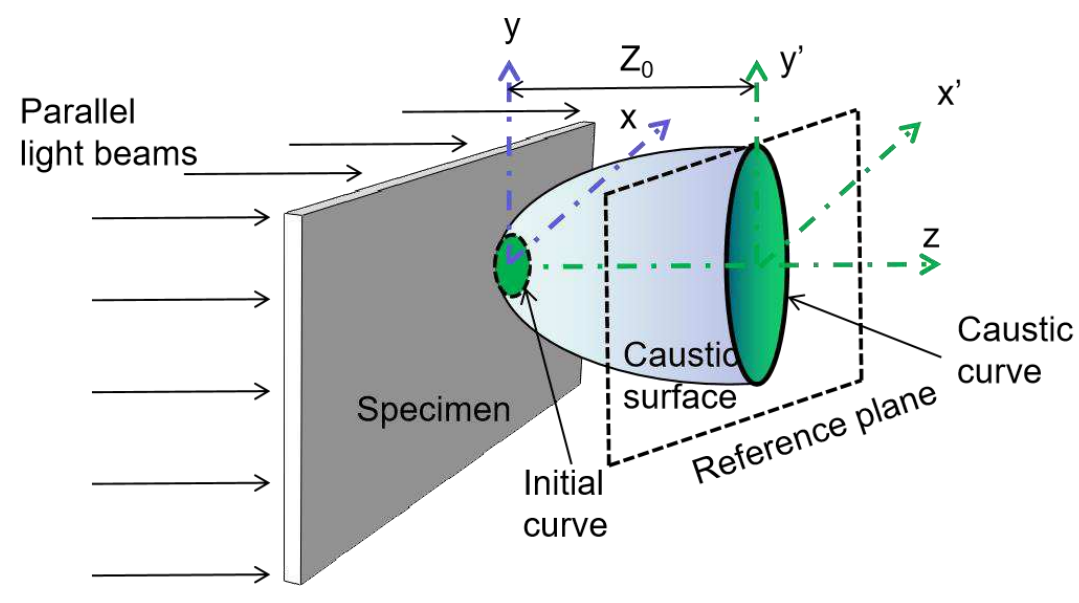

Fig.1 Caustic principle

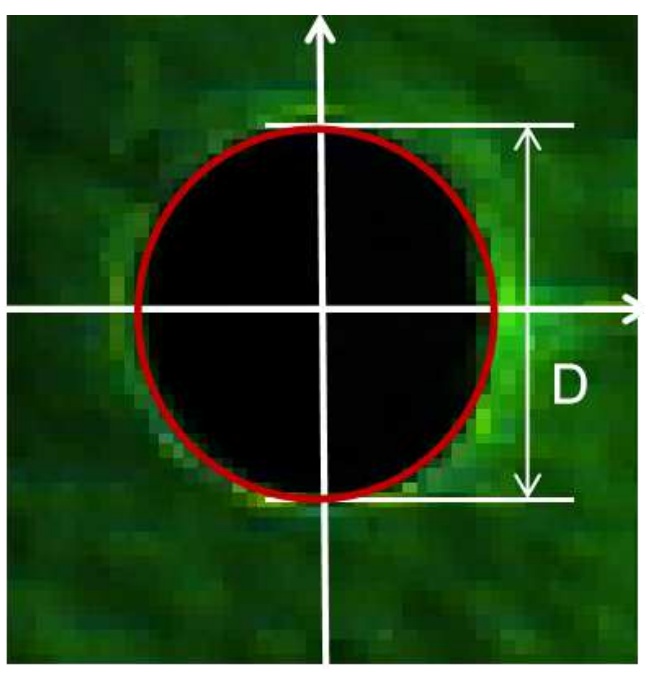

a)mode I caustic spots

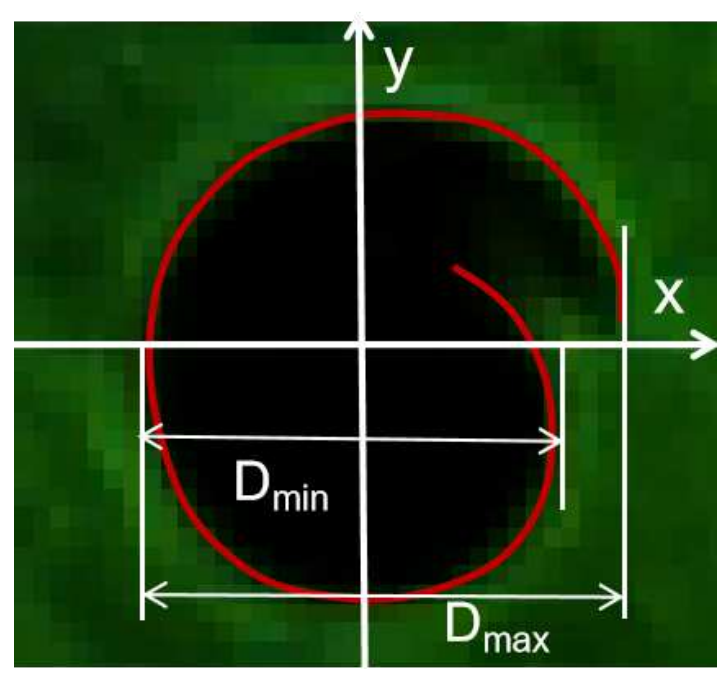

b)mixed mode I-II caustic spots

Fig.2 Two kinds of caustic images

When there is a point $T(x, y)$ on the specimen, there will be a corresponding point $T^{\prime}\left(x^{\prime}, y^{\prime}\right)$ on the reference surface, and their relationship can be expressed $\mathrm{as}^{34}$ :

$$
\vec{X}=\overrightarrow{\mathrm{x}}+\overrightarrow{\mathrm{w}}
$$

Where $\overrightarrow{\mathrm{w}}$ is the vector of the specimen deflected to the reference plane by the distance $Z_{0}$, which can be expressed as: 


$$
w=-Z_{0} \operatorname{grad} \Delta s_{\mathrm{r}, t}(x, y)
$$

$\Delta \mathrm{s}_{r, t}$ refers to the variation of light passing through the specimen, which can be expressed as:

$$
\Delta \mathrm{s}_{r, t}=\varepsilon d \mathrm{c}_{r, t}\left[\left(\sigma_{1}+\sigma_{2}\right) \pm \xi_{r, t}\left(\sigma_{1}-\sigma_{2}\right)\right]
$$

Where $\varepsilon$ is a constant, usually 1,$2 ; d$ is the thickness of the specimen; $\xi_{r, t}$ is the light anisotropy coefficient of the material; $\mathrm{c}_{r, t}$ is the stress optical constant;

If the growth of crack length after time $\Delta \mathrm{t}$ is set as $\Delta z$, the $\Delta z$ at any time $t_{\mathrm{i}}$ can be expressed as:

$$
\Delta \mathrm{z}\left(\mathrm{t}_{\mathrm{i}}\right)=\sqrt{\Delta x^{2}\left(t_{i}\right)+\Delta y^{2}\left(t_{i}\right)}
$$

Where $\Delta x\left(t_{i}\right)$ and $\Delta y\left(t_{i}\right)$ are the displacements in the $\mathrm{x}$ and $\mathrm{y}$ directions at time $t_{\mathrm{i}}$ during the crack propagation process. The crack growth rate $v$ can be obtained by the differential of crack length and time interval.

According to the caustics theory, the caustics curve equation of the specimen in the reference plane can be expressed as:

$$
\begin{aligned}
& \mathrm{x}^{\prime}=r_{0}\left[\cos \left(\theta+2 \operatorname{acrtan} \frac{\mathrm{K}_{\mathrm{II}}}{K_{\mathrm{I}}}\right)+\frac{2}{3} \cos \frac{3}{2}\left(\theta+2 \operatorname{acrtan} \frac{\mathrm{K}_{\mathrm{II}}}{K_{\mathrm{I}}}\right)\right] \lambda_{\mathrm{m}} \\
& \mathrm{y}^{\prime}=r_{0}\left[\sin \left(\theta+2 \operatorname{acrtan} \frac{\mathrm{K}_{\mathrm{II}}}{K_{\mathrm{I}}}\right)+\frac{2}{3} \sin \frac{3}{2}\left(\theta+2 \operatorname{acrtan} \frac{\mathrm{K}_{\mathrm{II}}}{K_{\mathrm{I}}}\right)\right] \lambda_{\mathrm{m}}
\end{aligned}
$$

Where $\lambda_{\mathrm{m}}$ is the magnification of light; $\mathrm{r}_{0}$ is the radius of the initial curve, which can be expressed as:

$$
\mathrm{r}_{0}=\left(\frac{3 \varepsilon Z_{0} d c_{r, t}}{2 \lambda_{m} \sqrt{2 \pi}}\right)^{\frac{2}{5}}\left(K_{\mathrm{I}}^{2}+K_{\mathrm{II}}^{2}\right)^{\frac{1}{5}}
$$

Therefore, mode I dynamic crack stress intensity factor $K_{\mathrm{I}}^{\mathrm{d}}$ and mode II dynamic crack stress intensity factor $K_{\mathrm{II}}^{\mathrm{d}}$ can be expressed as:

$$
\begin{gathered}
K_{I}^{\mathrm{d}}=\frac{2 \sqrt{2 \pi} F(v)}{3 g^{5 / 2} z_{0} c d} D_{\max }^{5 / 2} \\
K_{\mathrm{II}}^{\mathrm{d}}=\mu K_{I}^{\mathrm{d}}
\end{gathered}
$$

Among them, $g$ is the stress intensity factor coefficient, which is $3.17 ; D_{\max }$ is the maximum diameter of the caustics spot; $\mu$ is the scale factor; $F(v)$ is the speed adjustment factor, which can be expressed as:

$$
F(v)=\frac{4 \beta_{1} \beta_{2}-\left(1+\beta_{2}^{2}\right)^{2}}{\left(1+\beta_{2}^{2}\right)\left(\beta_{1}^{2}-\beta_{2}^{2}\right)}
$$

Where $\beta_{i}^{2}=1-\left(\mathrm{v} / c_{i}\right)^{2}, i=1,2, c_{1}$ and $c_{2}$ are the compressive and shear waves velocities, respectively. 


\subsection{Testing system}

The test combines a new digital laser dynamic caustics(DLDC) system with stress wave loading system(see in fig.3). The DLDC system mainly consisted of a high-speed digital camera(Fastcan-SA5(16G) : Photron Company, Japan), two convex lenses(focal length $1500 \mathrm{~mm}$ and diameter 300mm), a expander (LCht-3X-532 nm: Edmund Optics Company, USA), and a green laser(LWGL300-1500mW: $50 \mathrm{~mW}$ ). When the system works, the laser is emitted by the laser, diffuses after passing through the beam expander, and then passes through the convex lenses 1, PMMA specimen and convex lenses 2 respectively, and finally the image presented enters the high-speed camera.

SHPB experimental system is composed of a pneumatic power device, a bullet, an infrared velocimeter, an incident bar, and a damper. Compared with the traditional split Hopkinson bar, the stress wave loading system in this paper has no transmitted bar. The reason was that the wave impedance matching between the steel rod and the plexiglass is poor, and the stress wave transmission part is less, so the system is only used as a means of dynamic loading. The bullet and incident bar used in the experiment are cylindrical steel rods with length of $400 \mathrm{~mm}$ and $2000 \mathrm{~mm}$ respectively. The elastic modulus $E_{\mathrm{b}}$ of the bar is 206 $\mathrm{GPa}$, and the measured longitudinal wave velocity is $5123 \mathrm{~m} / \mathrm{s}$.

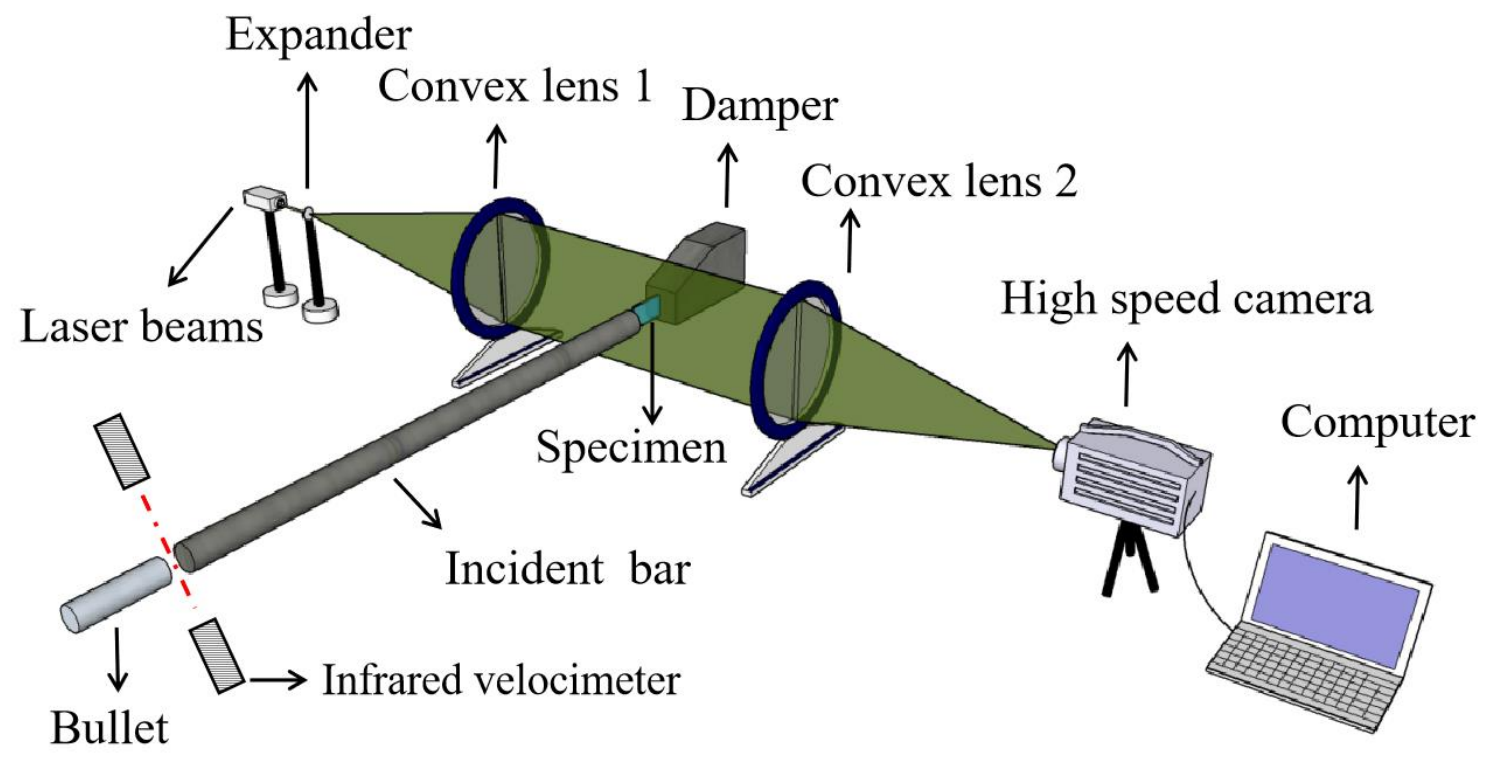

Fig.3 Testing system

Because of the movement difference between the contact surface of the bar and the specimen in the transverse direction, there is friction force in the test process. It will prevent the transverse deformation at the contact surface of the specimen and destroy the one-dimensional stress state of the test piece, causing abnormal damage to the test piece, as shown in Fig. 4. Therefore, during the impact experiment, it is necessary to lubricate the bars in contact with both ends of the test piece, such as applying vaseline. 


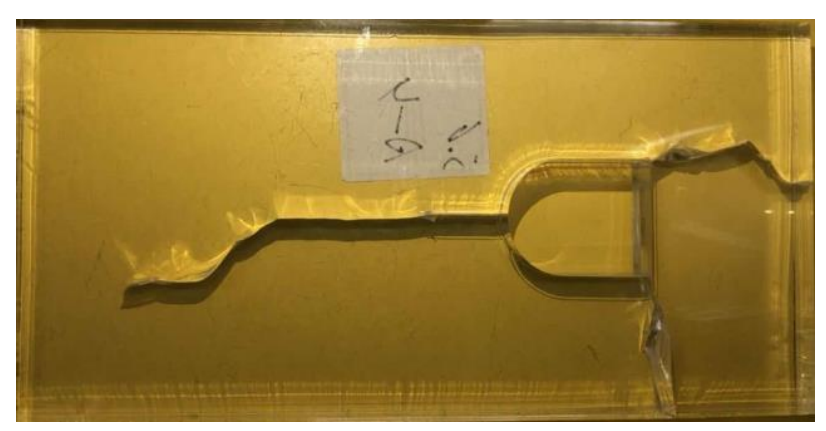

Fig.4 An abnormal failure caused by friction

\section{Experimental setup}

\subsection{Specimen design}

Figure 5 shows the geometric dimensions of the semi-circular arch roadway specimen. According to the actual engineering background, it is assumed that the width of the roadway is $8 \mathrm{~m}$, the height is $10 \mathrm{~m}$, and the radius of the semi-circular arch is $4 \mathrm{~m}$. According to the above conditions, similar simulation experiments were carried out, and the roadway size was reduced according to the similarity ratio of 400:1, and the test piece roadway width was $20 \mathrm{~mm}$, the height was $25 \mathrm{~mm}$, and the radius of the semi-circular arch was $10 \mathrm{~mm}$. At the same time, the length of the entire test piece is $140 \mathrm{~mm}$, the width is $70 \mathrm{~mm}$, and the thickness is $10 \mathrm{~mm}$. Prefabricated cracks with a length of $15 \mathrm{~mm}$ and a crack width of $0.5 \mathrm{~mm}$ are set at different positions on the top of the semi-circular arch. The material of the test piece is PMMA, and the relevant parameters of PMMA ${ }^{35}$ are shown in Table 1.

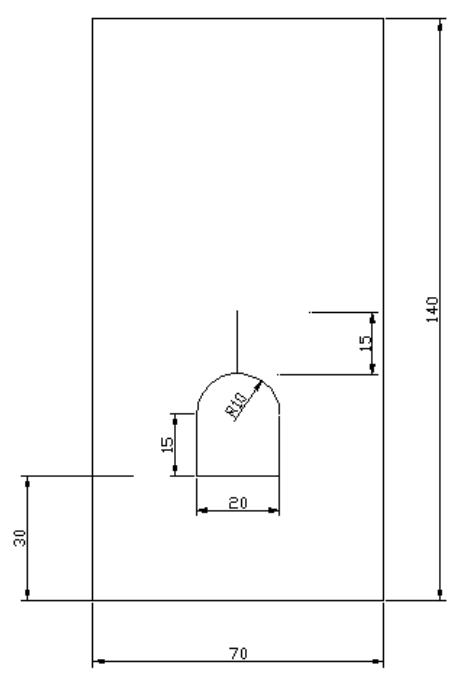

Specimen A

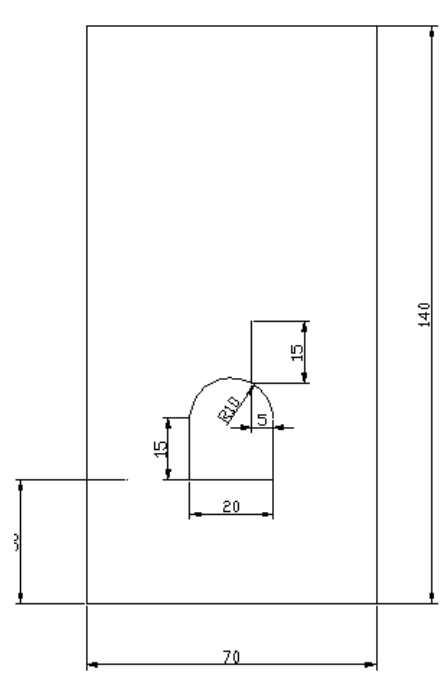

Specimen B

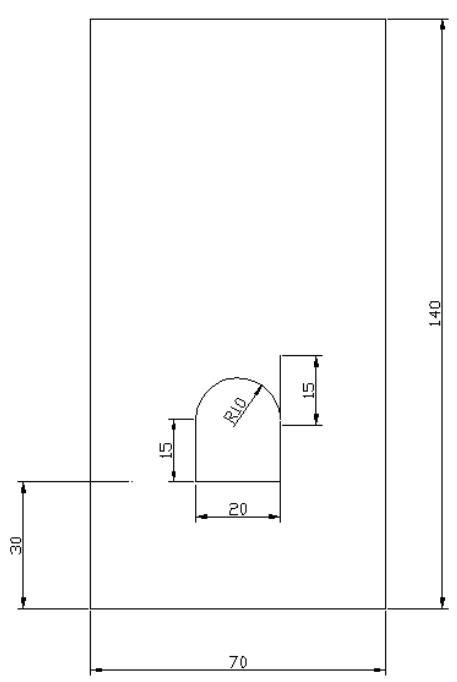

Specimen C

Fig.5 Specimen geometry

Table 1 Mechanical properties of $\mathrm{PMMA}^{35}$ 


\begin{tabular}{cccc}
\hline Mechanical properties & Symbols & $(\mathrm{Units})$ & PMMA \\
\hline Density & $\rho$ & $\left.\mathrm{kg} / \mathrm{m}^{3}\right)$ & 1180 \\
Dynamic Young's modulus & $E_{\mathrm{d}}$ & $(\mathrm{GPa})$ & 6.1 \\
Poisson's ratio & $V_{\mathrm{d}}$ & $(-)$ & 0.31 \\
Velocity of compressive & $C_{\mathrm{p}}$ & $(\mathrm{m} / \mathrm{s})$ & 2320 \\
waves & $C_{\mathrm{s}}$ & $(\mathrm{m} / \mathrm{s})$ & 1260 \\
Velocity of shear waves & $C$ & $\left(\mathrm{~m}^{2} / \mathrm{N}\right)$ & $0.88 \times 10-10$ \\
Stress optical constant & $G$ & $(\mathrm{GPa})$ & 1.28 \\
Shear modulus & $G$
\end{tabular}

In order to make the crack propagate smoothly, an initial crack was machined at different positions on the top of the semi-circular arch. Due to the influence of incident bar size, the specimen size is difficult to reach infinity. At the same time, it is necessary to ensure that the semi-circular arch tunnel in the middle of the specimen has a certain size. In order to reduce the influence of the boundary of the test piece on the propagation of cracks, when designing the size of the test piece, the width of the test piece is slightly larger than the diameter of the incident bar $(50 \mathrm{~mm})$. This can ensure that when the stress wave is transmitted to the specimen, all cracks within the purple dotted line are affected by stress waves(Figure 6).In this way, the interference of the upper and lower boundaries on the crack propagation is reduced. The principle of specimen length selection is as long as possible. Due to the influence of the elastic modulus, shear modulus and thickness of the test piece itself, in order to prevent the test piece from longitudinally breaking from the middle part during the impact process, the better size obtained through repeated experiments is $140 \mathrm{~mm}$ in length. In many sets of tests, the propagation of cracks is usually in the purple area, and very few tests show that the cracks propagate to the red area., When the crack propagates to the red region, the crack propagation is affected by the left boundary and deflects suddenly, as shown in Figure 7. Therefore, the scope of the study of crack propagation in this paper is within the purple dash.

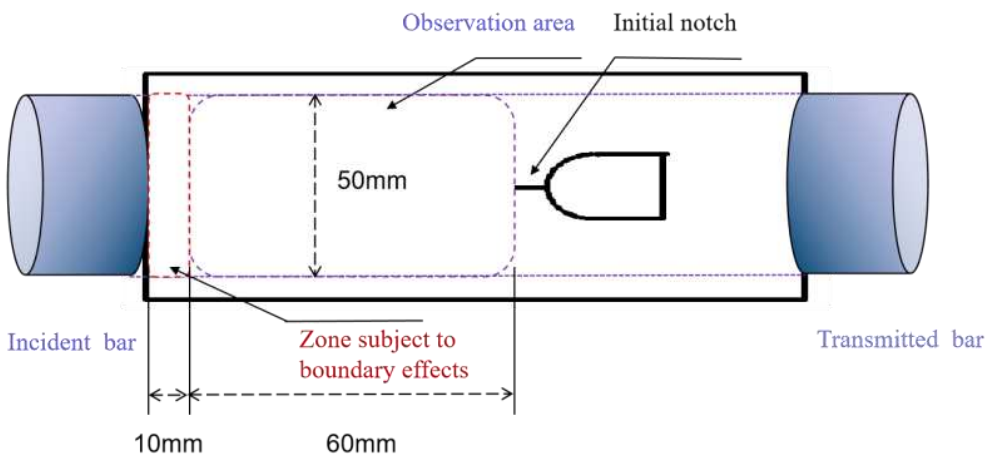

Fig.6 Schematic diagram of specimen 


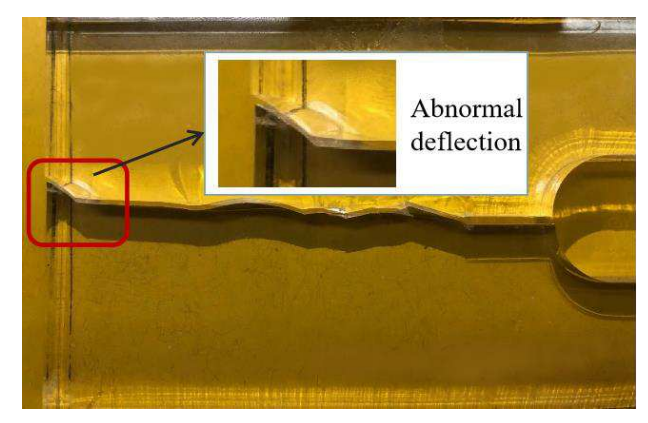

Fig.7 Subject to boundary effects

\subsection{Test Operation}

To set up a DLDC system, it is important to place all equipment in a suitable horizontal position to ensure that the laser can be perpendicular to the surface of the specimen. The resolution of high-speed camera is $65100 \mathrm{fps}$ and the pixel is $448 \times 224$. During the test, the experimenter $\mathrm{Li}$ was responsible for adjusting the incident pressure of the bullet. In order to control the loading rate as same as possible, the air pressure should be between $0.2 \pm$ $0.01 \mathrm{Mpa}$. When experimenter Zhang heard the impact sound, he immediately pressed the video button. In this experiment, the high-speed camera adopts post trigger mode, which can record the picture within $2 \mathrm{~s}$ before pressing the button, so as to ensure that the test process can be completely recorded. After the test, according to the velocity measured by infrared velocimeter, the test records of three groups of specimens (with different crack positions) were randomly selected as the test results. The results are shown in Table 2. It can be found that the emission pressure and velocity of specimen A, B and C are almost the same.

Table 2 The bullet velocity and pressure corresponding to different specimens

\begin{tabular}{cccc}
\hline $\begin{array}{c}\text { Air pressure } \\
(\mathrm{MPa})\end{array}$ & 0.2 & 0.2 & 0.21 \\
\hline $\begin{array}{c}\text { Bullet velocities } \\
(\mathrm{m} / \mathrm{s})\end{array}$ & 4.53 & 4.51 & 4.52 \\
Specimen & Specimen A & Specimen B & Specimen C \\
\hline
\end{tabular}

\section{Results and Discussion}

\subsection{Crack propagation path of specimen}

Figure 8 shows the crack propagation path of three groups of semi-circular arch roadway specimens with different crack positions. The prefabricated crack of specimen A is located on the central axis of the specimen, and after being impacted, it expands approximately in a straight line along the central axis, and fluctuates up and down in a small range. The 
prefabricated crack of specimen B is 5mm away from the central axis, and the specimen will bend downward to form an approximate circular arc after being impacted. When it extends near the central axis, it almost does not expand in the vertical direction. The prefabricated crack of specimen $\mathrm{C}$ is located at the edge of semi-circular arch roadway, and the crack propagation is similar to that of specimen B. However, the degree of circular extension of specimen $\mathrm{C}$ is more obvious than that of specimen B. Similarly, specimen $\mathrm{C}$ does not continue to expand downward after extending to the central axis, but moves horizontally along the central axis.

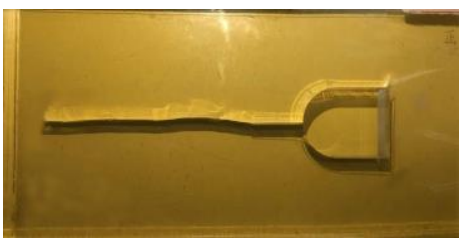

a) Specimen A

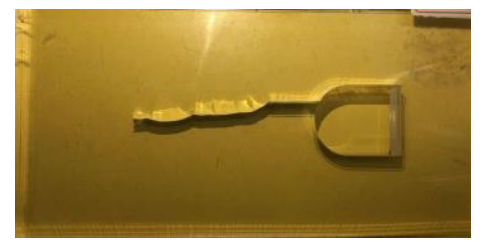

b) Specimen B

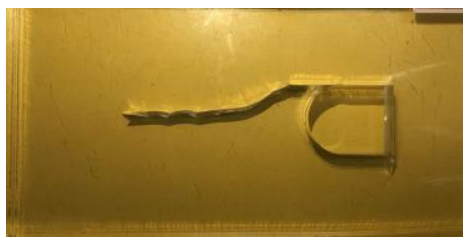

c) Specimen C

Fig.8 Crack growth trace

\subsection{Dynamic caustics diagram at typical moments}

Due to space limitations, Figure 9 shows the partial caustics diagrams of specimens A, B, and $\mathrm{C}$ at different moments with prefabricated cracks in different positions. It should be noted that the time regulation in this article is that the moment before the caustic spots changes is 0 . It can be found that even if the prefabricated cracks positions are different, the caustics spot area of the prefabricated cracks tip has undergone a process of change from small to large at the initial stage of impact on the three sets of specimens. It shows that the increase of caustic spots at this stage is only caused by the impact load acting on the crack tip to cause energy concentration. When the energy accumulated at the crack tip reaches a certain level, the crack begins to expand, that is, the caustic spots moves.

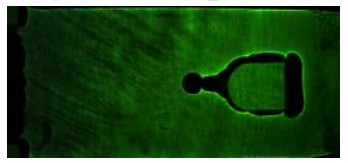

$t=46.08 \mathrm{us}$

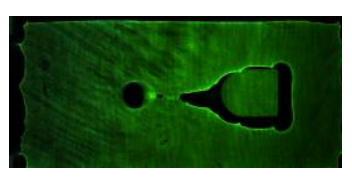

$t=1520.73 \mathrm{us}$

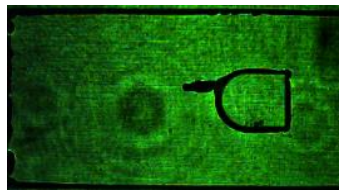

$t=13.33 \mathrm{us}$

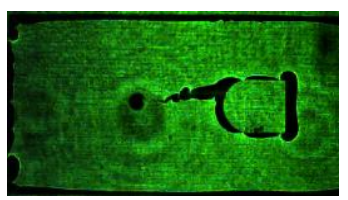

$t=973.33 \mathrm{us}$

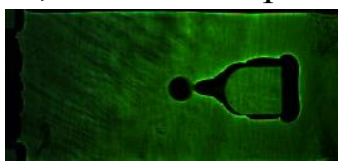

$t=276.49 \mathrm{us}$

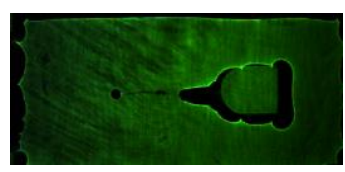

$t=2457.75$ us

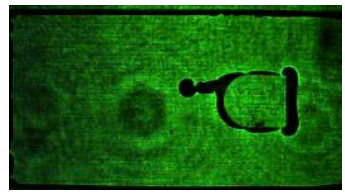

$t=93.33 \mathrm{us}$

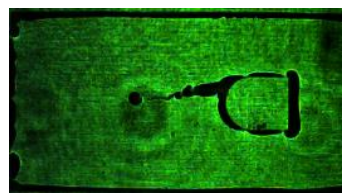

$t=1213.33$ us

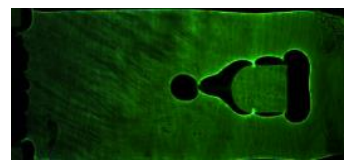

$t=829.49 \mathrm{us}$

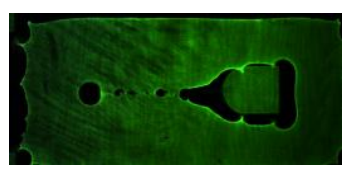

$t=2749.61$ us

a)Specimen A

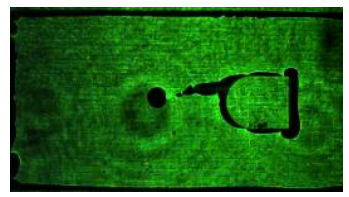

$t=466.66 \mathrm{us}$

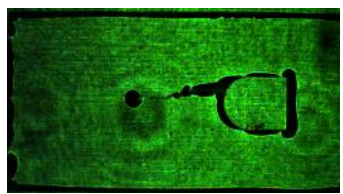

$t=1466.66 \mathrm{us}$

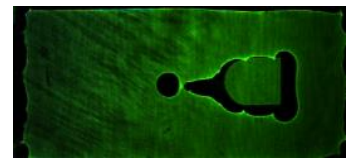

$t=1182.79 \mathrm{us}$

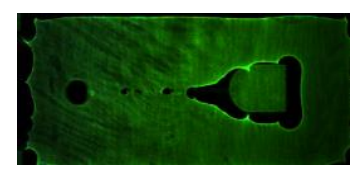

$t=2903.22 \mathrm{us}$

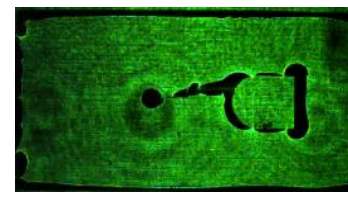

$t=920 \mathrm{us}$

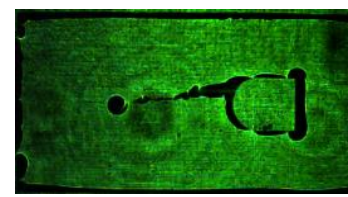

$t=1840 \mathrm{us}$ 

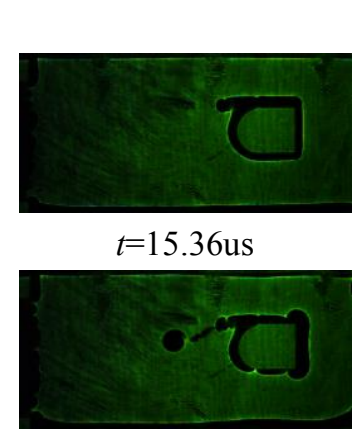

$t=1182.79$ us

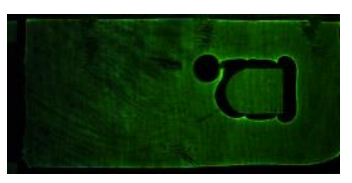

$t=138.24 \mathrm{us}$

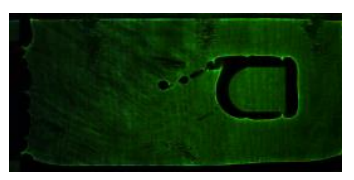

$t=1290.32$ us
b)Specimen B
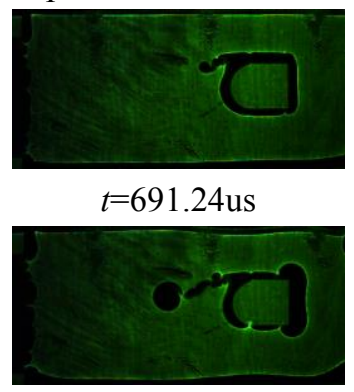

$t=1643.62 \mathrm{us}$

o) Specimen C

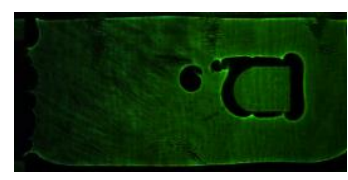

$t=921.65$ us

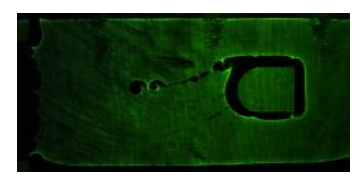

$t=2319.5$ us

Fig.9 Dynamic caustic image patterns at crack in specimens under different locations of prefabricated cracks

From the caustic spots image of specimen A, it can be found that the shape of the caustic spots at the crack tip at any moment is similar to the type I caustic spots in Fig. 2(a). Combining with the crack propagation trajectory of specimen A (shown in Fig. 8), it can be judged that when the prefabricated crack is at the central axis of the semi-circular arch roadway, the crack propagation after the specimen is impacted conforms to the mode I crack propagation law. At the same time, it can be found from Figure 9 that during the crack propagation process, the size of the caustic spots is not always in a large area.Sometimes it suddenly becomes smaller and then becomes larger.

From the caustic spots pattern of specimen B in Fig. 9, it can be found that the shape of the caustic spots sometimes conforms to the I-II mixed type caustic pattern in Fig. 2 (b) during crack propagation, for example, $t=93.33$ us. Sometimes the shape conforms to the type I caustics in Fig. 2 (a), for example, $\mathrm{t}=466.66$ us. The results show that the crack propagation process is mixed mode I and I-II when the location of the prefabricated crack is $5 \mathrm{~mm}$ away from the central axis. After the crack stops growing, the shape of the caustic becomes smaller and smaller, and its shape changes from mixed mode I-II to type I.

Through the caustic spots of specimen $\mathrm{C}$, it is found that before the crack begins to move, the size of the caustic spots at the tip of the preformed crack changes constantly. This reflects that the energy at its tip is constantly changing. At the initial stage of energy accumulation, the shape of the caustics is similar to that of a circle, which indicates that it conforms to type I caustics. When the crack begins to move, the shape of the caustic spots conforms to the I-II mixed type caustic pattern in Fig. 2 (b), and its size is also changing constantly. When the crack stops growing, the shape of the caustics becomes mode I.

\subsection{Dynamic stress intensity factor at crack tip (DSIF)}

Due to the limitation of the exposure time of high-speed camera, the outer edge of the image captured by the moving caustic spots will be blurred. This ambiguity is the main reason for the error in the test results. Therefore, use the deblurring technology and binarization technology in MATLAB to focus on the caustic spots contour. It can be seen from formula (8) and formula (9) that regardless of whether it is $K_{\mathrm{I}}^{\mathrm{d}}$ or $K_{\mathrm{I}}^{\mathrm{d}}$, its size has a linear relationship with the five-seconds power of the caustic spot diameter. If the caustic spots contour processing is not accurate enough, the error of the calculated DSIF value will be magnified many times. Therefore, after the caustic spots contour is perfectly processed, professional measurement software is needed to obtain the most accurate caustic spots diameter. 
Since the fracture process of the specimen is the result of multiple actions after the internal stress wave is reflected, the entire fracture process takes a long time. Through data processing, it is found that the DSIF change law of the whole process is roughly similar, and the change curve is almost the same in multiple time periods. Therefore, the change of DSIF during the first half of the fracture process is selected for analysis. Through the caustics method, the curve of the dynamic stress intensity factor at the crack tip of different specimens can be calculated with time(shown in Fig.10). Here, the period from the moment before the crack tip caustic speckles starts to appear to the movement of the caustic spots is defined as the initial energy accumulation stage (IEAS). The IEAS time of specimens A, B and C are 261.13 us, 120us, and 122.88 us respectively. When the prefabricated crack is on the central axis, the energy accumulation takes longer, and when the prefabricated crack shifts to the edge of the semi-circular arch, the IEAS time becomes shorter.

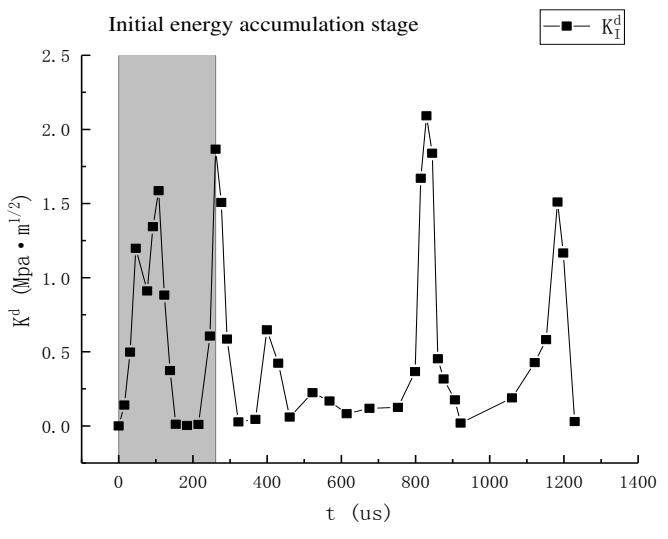

a) Specimen A

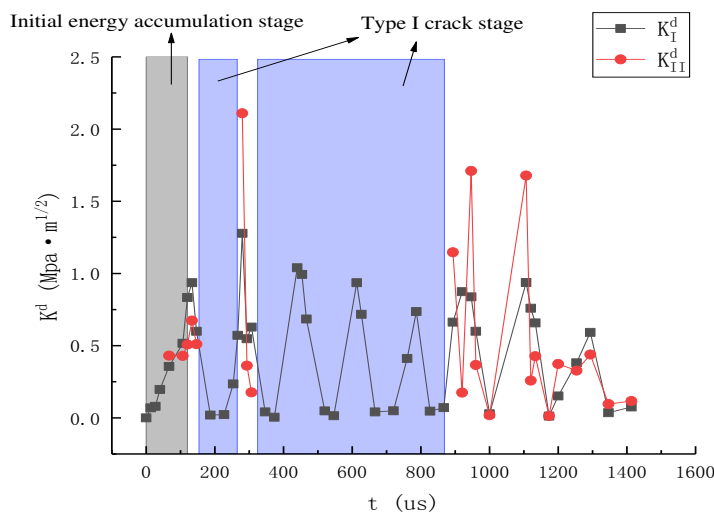

b)Specimen B

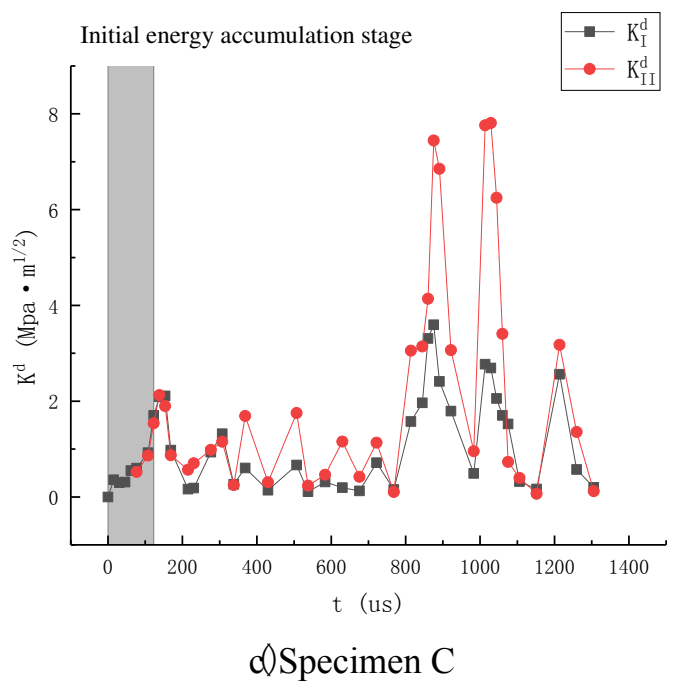

Fig.10 The DSIF-time curve under different specimen

The prefabricated crack of the specimen is on the central axis. When the specimen is impacted, the crack tip energy starts to converge. In Figure 9(a), the correspondingly shows that the size of the caustic spots changes. When $K_{\mathrm{I}}^{\mathrm{d}}=1.81 \mathrm{MPa} \cdot \mathrm{m}^{1 / 2}$, the crack begins to move. The results show that the mode I fracture toughness of the specimen is $1.81 \mathrm{MPa} \cdot \mathrm{m}^{1 / 2}$ when the prefabricated crack is on the central axis. After the end of energy accumulation stage, the value of dynamic stress intensity factor is constantly changing, reaching the maximum value of $2.40 \mathrm{MPa} \cdot \mathrm{m}^{1 / 2}$. From the impact of the crack until the caustic spots no longer changes, 
only $K_{\mathrm{I}}^{\mathrm{d}}$ exists in the whole process, which is a pure type I crack propagation.

From Figure $10(\mathrm{~b})$, it can be found that when $K_{\mathrm{I}}^{\mathrm{d}}=0.83 \mathrm{MPa} \cdot \mathrm{m}^{1 / 2}, K_{\mathrm{II}}^{\mathrm{d}}=0.50 \mathrm{MPa} \cdot \mathrm{m}^{1 / 2}$ the crack starts to move. It shows that when the prefabricated crack is $5 \mathrm{~mm}$ away from the central axis, the fracture toughness of type $\mathrm{I}$ is $0.83 \mathrm{MPa} \cdot \mathrm{m}^{1 / 2}$, and the fracture toughness of type II is $0.50 \mathrm{MPa} \cdot \mathrm{m}^{1 / 2}$. In the process of crack growth, it is not simply a type I crack growth or a mixed type I-II growth, but a type I and a mixed type I-II appear alternately. When $t=150 \mathrm{us}-266.66 \mathrm{us}, \mathrm{DSIF}$ only has $K_{\mathrm{I}}^{\mathrm{d}}$. When $t=266.66 \mathrm{us}-320 \mathrm{us}, K_{\mathrm{I}}^{\mathrm{d}}$ and $K_{\mathrm{II}}^{\mathrm{d}}$ exist at the same time. When $t=320 \mathrm{us}-866.66 \mathrm{us}$, the DSIF value is re-stored to only $K_{\mathrm{I}}^{\mathrm{d}}$. From $t=866.66$ us-1413.33us, DSIF shows a mixed I-II type.

For specimen $\mathrm{C}$, when $t=0 \mathrm{us}-61.44 \mathrm{us}$, there was only as $K_{\mathrm{I}}^{\mathrm{d}}$, and the pattern of caustic speckle was pure I type. After 61.44us, I-II mixed type caustic speckle appeared. When $t=$ 122.88 us, the crack tip completed the energy accumulation stage and then began to propagate. The fracture toughness of type I is $1.70 \mathrm{MPa} \cdot \mathrm{m}^{1 / 2}$, and the fracture toughness of type II is $1.53 \mathrm{MPa} \cdot \mathrm{m}^{1 / 2}$. The maximum value of $K_{\mathrm{I}}^{\mathrm{d}}$ is $3.59 \mathrm{MPa} \cdot \mathrm{m}^{1 / 2}$, and the maximum value of $K_{\mathrm{II}}^{\mathrm{d}}$ is $7.80 \mathrm{MPa} \cdot \mathrm{m}^{1 / 2}$. But the maximum value of $K_{\mathrm{I}}^{\mathrm{d}}$ and $K_{\mathrm{II}}^{\mathrm{d}}$ is not reached at the same time.

\subsection{Influence of the location of prefabricated crack on crack propagation}

In order to be able to see the concrete situation of the crack in the process of motion intuitively, the moving image of caustic spot is processed. Taking the tip of the prefabricated crack as the origin $\mathrm{O}$, the horizontal left direction is the positive direction of $\mathrm{X}$, and the vertical downward direction is the positive direction of $Y$. The curves of the displacement of the crack tip in the $\mathrm{X}$ direction and $\mathrm{Y}$ direction with time are drawn, and also take the crack change in the first half of the fracture process for analysis(shown in Fig. 11).

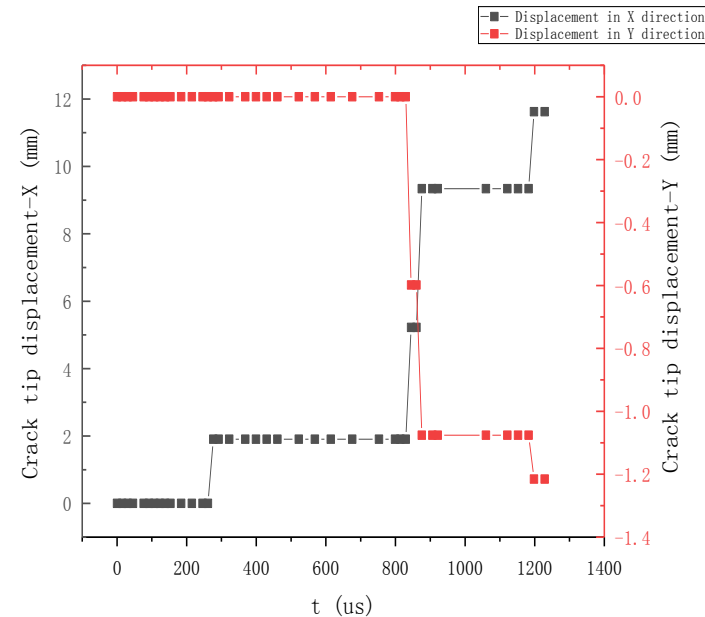

a) Specimen A

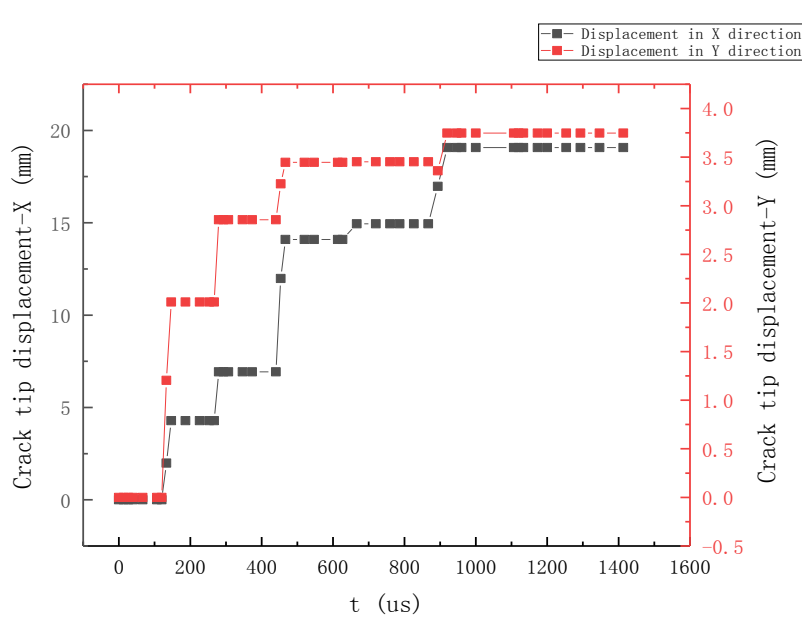

b)Specimen B 


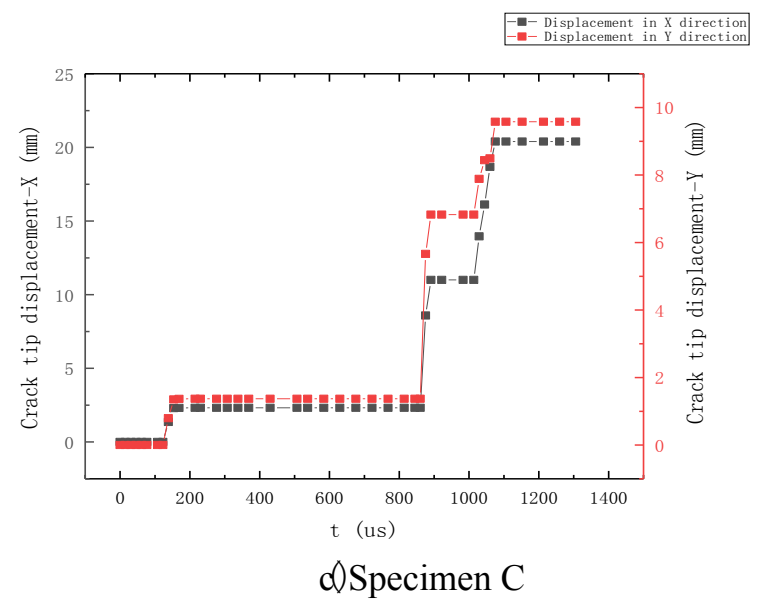

Fig.11 Crack tip propagation time history curve

From Figure 11, it can be intuitively found that the displacement-time diagrams of the crack tips of the three groups of specimens in the $\mathrm{X}$ and $\mathrm{Y}$ directions all present a stepped curve. Explain that under the action of impact load, crack propagation is not completed at once. Instead, it pauses after extending a certain distance, and then expands again when the energy accumulates to a certain value. The continuous change of DSIF in Figure 10 can prove this phenomenon from the side. Due to the energy consumption of crack growth, the DSIF of the crack tip becomes smaller during movement. When the value drops below the crack fracture toughness, the crack stops expanding. After waiting for the energy to accumulate and exceed the fracture to ughness again, the crack continues to grow. In Figure 11(a), when the crack expands along the central axis, the crack floats upward in a small range, so that its displacement in the $\mathrm{Y}$ direction will be negative. However, according to the change of caustic spots in Figure 9(a), it is believed that the crack propagation of specimen A confor -ms to the pure type I law. Figure 11(b) shows that the displacement of the cracks $i$ $\mathrm{n}$ the $\mathrm{X}$ and $\mathrm{Y}$ directions are almost synchronous. At the end of the crack propagatio $\mathrm{n}$ trajectory, it can be found that specimen $\mathrm{B}$ still has a small range of displacement in the $\mathrm{Y}$ direction, which is consistent with the actual specimen fracture trajectory in Figure $8(\mathrm{~b})$. It can be found that the displacement time in $\mathrm{Y}$ direction is relatively concentrated(shown in Fig. 11(c)), and it is almost completed in $t=860.21 \mathrm{us}-1075.26 \mathrm{u}$ s. In other time periods, there is only a small range of $\mathrm{Y}$-direction displacement.

When the preformed crack is in the central axis, the crack growth belongs to $p$ ure mode I. The energy of impact load mainly makes the crack move in X direction. When the prefabricated crack moves upward, the mixed mode of I-II appears. With the increase of displacement of prefabricated crack, the displacement of crack in $\mathrm{Y}$ direction increases. 


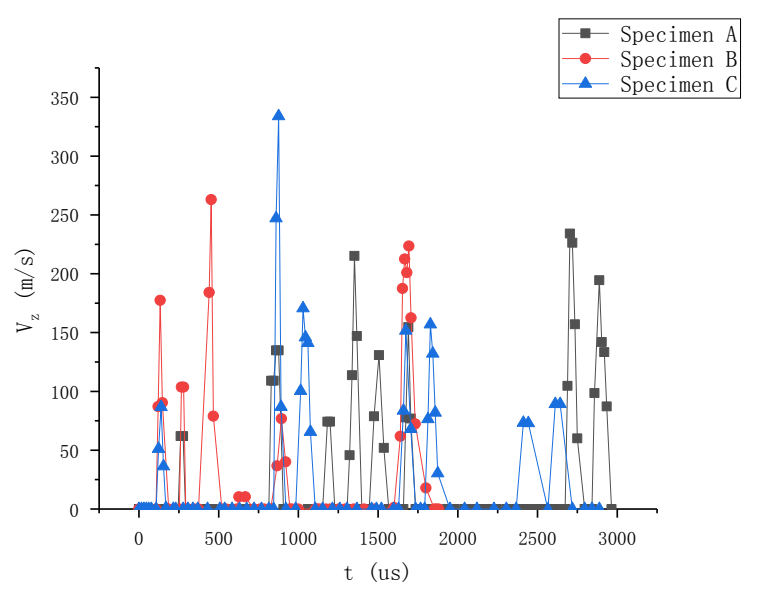

Fig. 12 The $V_{z}$ velocity of crack growth varies with time

According to formula (4), the displacement of the crack in the $\mathrm{X}$ direction and the $\mathrm{Y}$ direction is combined vector to obtain the actual displacement $\Delta z$. Then calculate the derivative of the displacement $\Delta z$ with respect to time, and get the crack growth rate $V z$ with time (as shown in Fig. 12). It can be found that when the prefab ricated crack is $5 \mathrm{~mm}$ away from the central axis, its speed reaches the maximum tim $\mathrm{e}$ is the earli-est, followed by the prefabricated crack at the edge of the semi-circular arch roadway, and the prefabricated crack at the central axis reaches the maximum at the latest. As the prefabricated crack shifts upward from the central axis, the ma ximum speed reached during the crack propagation process gradually increases. The $f$ irst time the stress acts on the crack tip is mainly to make the crack tip energy conv erge. When the fracture toughness of the specimen is reached, the crack movement has speed. With the disappearance of the tip stress, the crack velocity decreases grad ually, and when the reflection stress acts on the crack tip again, the crack speed incr eases again.

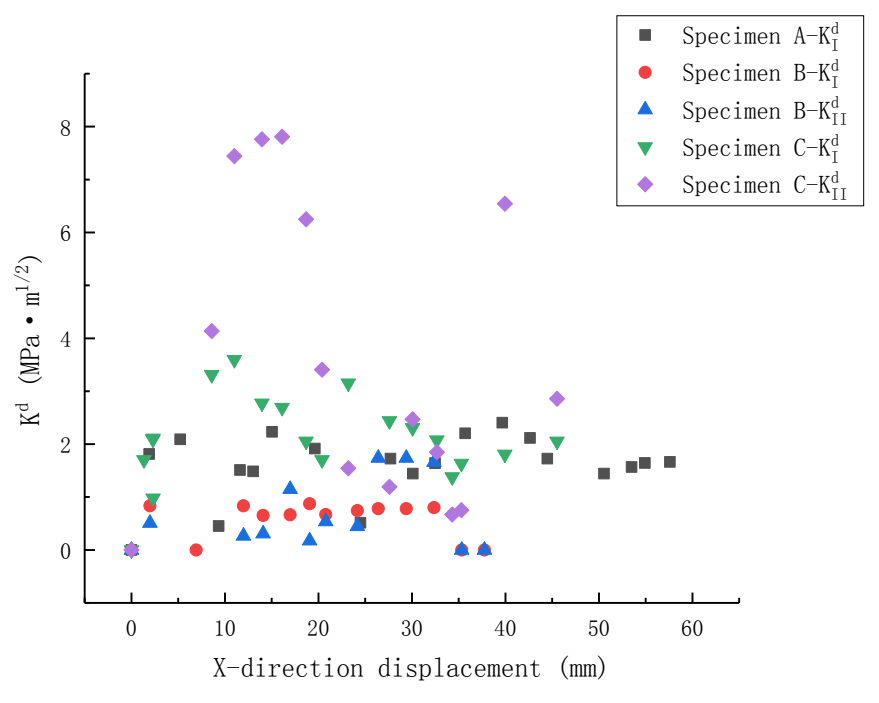

Fig.13 Crack propagation DSIF varies with displacement in X direction

Figure 13 is a scatter plot of DSIF varying with the displacement length in the $\mathrm{X}$ dir ection during the crack propagation process when the pre-crack positions are different. It could be found that when the cracks of the three groups of specimens extend to $t$ 
he same length, the $K_{\mathrm{I}}^{\mathrm{d}}$ and $K_{\mathrm{II}}^{\mathrm{d}}$ of specimen $\mathrm{C}$ were larger. It shows that when a sing le pre-formed crack is at the edge of a semi-circular arched roadway, more energy wi 11 be collected at the crack tip during the crack propagation process after impact. The $K_{\mathrm{I}}^{\mathrm{d}}$ and $K_{\mathrm{II}}^{\mathrm{d}}$ of specimen B were the smallest when the crack propagates to the sa me position, indicating that the crack propagation was relatively simple when the pref abricated crack is in the middle of the roadway edge and the central axis. According to Figure 10, it could be known that the time of the energy collection phase of spe cimen B was the shortest, and the initial fracture toughness was also the lowest.

\subsection{Crack growth process analysis}

The reason for the suspension of crack growth and the dramatic change of DSIF is that when the specimen is subjected to stress wave, a part of the stress wave acts on the crack tip, and a part of the stress wave is transmitted to the damper along the $s$ pecimen. So that the energy can-not be completely applied to the crack tip, so the cr ack will stop after a period of propagation. It can be seen from literature ${ }^{36}$ that when the contact surface between the test piece and the bar is smaller, the specific gravity of the reflected wave is larger, and the specific gravity of the transmitted wave is $\mathrm{s}$ maller. Therefore, part of the stress wave transmitted to the right side of test piece will be reflected back to the specimen, and transmitted back and forth inside the spec imen, causing the DSIF of the crack tip to continuously change. When the DSIF of $t$ he crack tip again exceeds the fracture toughness of the material, the crack continues to grow.

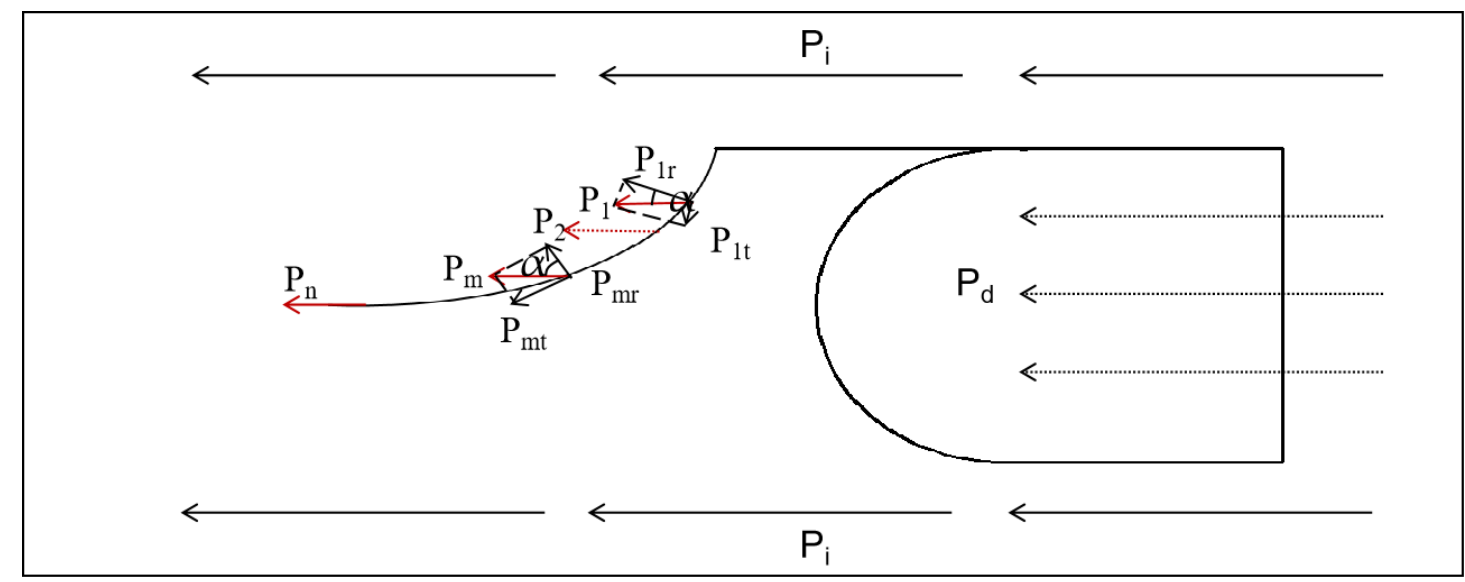

Fig. 14 Effect of stress wave on crack

Fig. 15 is a simplified schematic diagram of the effect of reflected stress wave on crack. When there is energy accumulation at the tip of the prefabricated crack fort he first time, due to the existence of semicircular arch roadway, the stress wave will attenuate to form $\mathrm{P}_{d}$ when it is transmitted to the nearby area. However, the stre-ss wave $\mathrm{P}_{i}$ on both sides of the semicircular arch roadway does not pass through t-he $\mathrm{r}$ oadway, so $\mathrm{P}_{i}$ will be greater than $\mathrm{P}_{d}$. Therefore, the displacement of the crack t-ip af ter the energy accumulation is completed will deflect downward rather than upw-ard. In t-he process of crack motion, it is still under the action of stress wave. Since the crack motion trajectory is an arc, the stress wave is decomposed in the normal and $\mathrm{t}$ angential directions of the arc to obtain $\mathrm{P}_{r}$ and $\mathrm{P}_{t}$, which can be expressed as: 


$$
\left\{\begin{array}{l}
P_{1 r}=P_{1} \cdot \cos \alpha, P_{1 t}=P_{1} \cdot \sin \alpha \\
P_{2 r}=P_{2} \cdot \cos \alpha, P_{2 t}=P_{2} \cdot \sin \alpha \\
\cdot \\
P_{m r}=P_{m} \cdot \cos \alpha, P_{m t}=P_{m} \cdot \sin \alpha
\end{array}\right.
$$

As $\alpha$ increases, the normal component of the stress wave gradually decreases, while the tangential component gradually increases. When $\alpha=90^{\circ}$, the normal component of the stress wave is 0 , and the crack no longer moves in a curve. The tangential component reaches the maximum, which is equal to the magnitude of the stress wave at this time.

\section{Numerical simulation}

In order to better verify the crack propagation law of the semi-circular arch roadway under impact, the commercial software ABAQUS is used to simulate the crack fracture process .The extended finite element method (XFEM) in ABAQUS is widely used to study the deformation and fracture of solid materials under force.

\subsection{Numerical model of specimen}

In the simulation, it is assumed that the change of the material is completely caused by the crack propagation. In order to ensure that both the experimental and simulated impact loads are subjected to uniform one-dimensional loads, the output terminal composed of the bullet and the incident bar is used for modeling (the output terminal load is the same as the test). The shear modulus of bullet and incident rod $G_{2}=81 \mathrm{G}-\mathrm{P}$ a, Poisson's ratio $V_{\mathrm{d} 2}=0.26$, material density $7900 \mathrm{~kg} / \mathrm{m}^{3}$. The bullet model and the in-ci dent bar model are composed of 412 and 1326 elements respectively, and the grid $\mathrm{s}$ ize is $10 \mathrm{~mm}$ (Figure 15). The shear modulus of PMMA is $G_{1}=1.28 \mathrm{GPa}$, Poisson's rati o $V_{\mathrm{d} 1}=0.31$, and material density is $1180 \mathrm{~kg} / \mathrm{m}^{3}$. The specimen is modeled by CPS4R solid elements, composed of 45706 elements, and the grid size is $0.05 \mathrm{~mm}$. The grid of the typical specimen is shown in Figure 16.

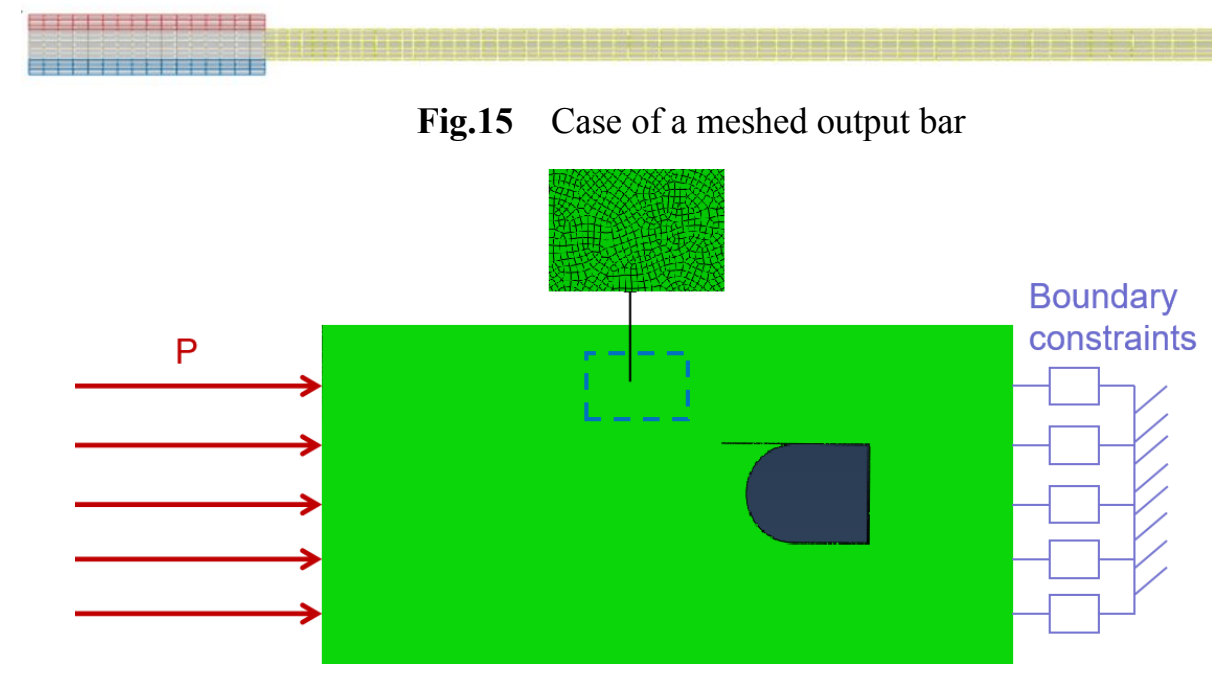


Fig.16 Typical mesh in ABAQUS

\subsection{Simulation results and discussion}

Figure 17 shows the simulated crack propagation trajectory of the specimen after fracture. The crack propagation track of the specimen obtained by test and simulation is compared, and Figure 18 is obtained. It can be found that the simulation result of $\mathrm{sp}$ eci-men $\mathrm{A}$ is a straight line extending along the central axis, and the actual test resul $\mathrm{t}$ will have a small expansion in the $\mathrm{Y}$ direction. The simulation results of specimen $\mathrm{s} \mathrm{B}$ and $\mathrm{C}$ are roughly the same as the actual test results, but the expansion path obt a-ined by the simulation results is smoother, while the path obtained by the actual tes $\mathrm{t}$ will fluctuate up and down in a few cases. This is related to the machining accurac $y$ of the test material and the nature of the material itself. In the simulation, it is co ns-idered that both ends of the specimen are completely flat and smooth, and the spe ci-men material is completely uniform. However, it is difficult to achieve this conditio $\mathrm{n}$ in practice, so it may result in the actual test that the crack growth path will fluc tua-te up and down in a small range.

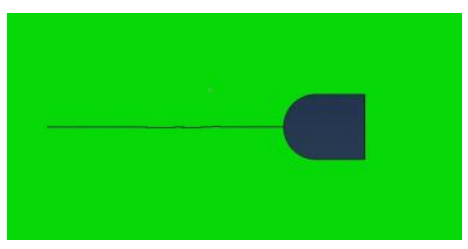

Specimen A

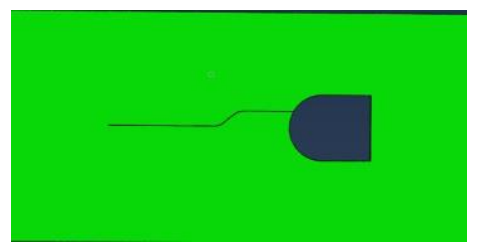

(b) Specimen B

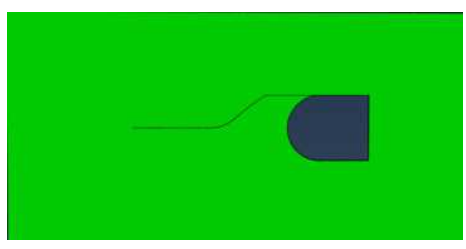

(c) Specimen C

Fig.17 Simulation of crack propagation for three types of specimens under

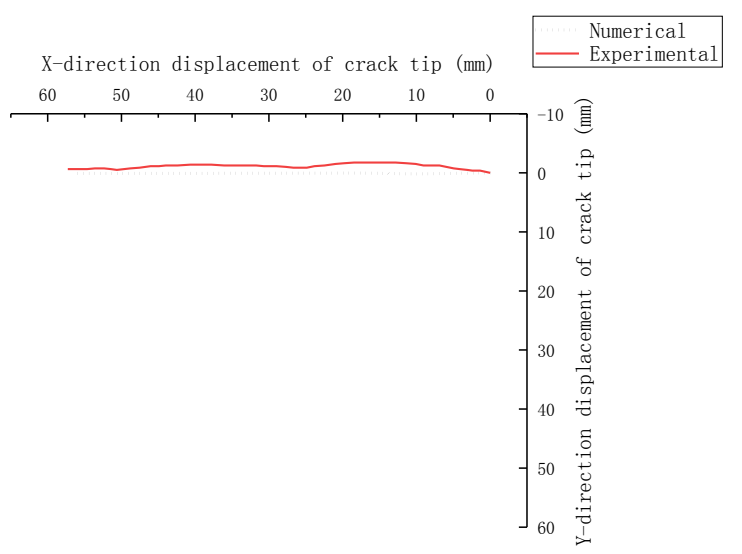

a)Specimen A

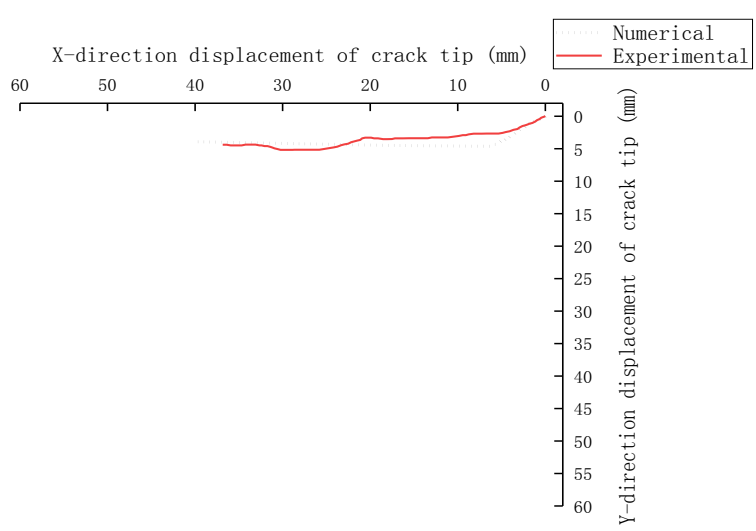

b)Specimen B 


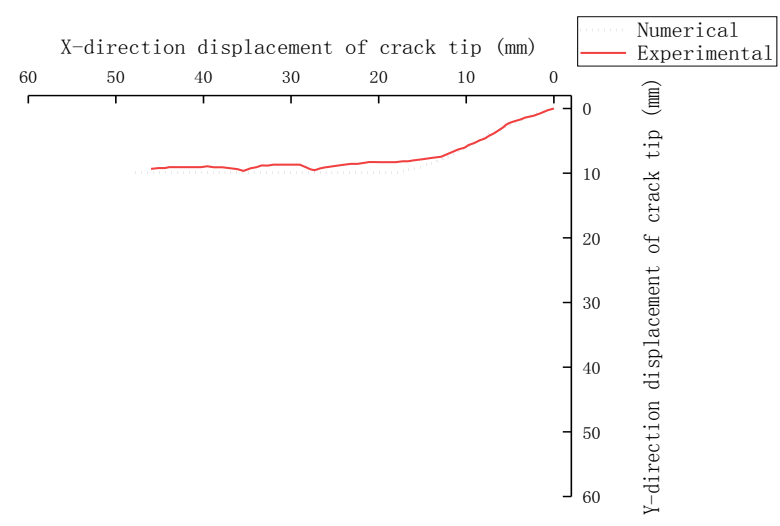

c) Specimen C

Fig.18 Comparison of crack paths

\section{Conclusions}

When the defect is at different positions of the semi-circular arch roadway, the crack propagation condition will be different after the external impact load. Therefore, it is very important to study the impact of the defect location on the roadway. The DLDC system and the SHPB system can be used to study the propagation of cracks under one-dimensional stress. Combined with ABAQUS software for numerical simulation, the following conclusions are obtained:

(1) When the prefabricated crack is at the central axis, the crack propagation is pure I type. When the prefabricated crack is located at a distance of $5 \mathrm{~mm}$ from the central axis, the crack growth is alternately type I and mixed type I-II. When the prefabricated crack is at the edge of the roadway, the crack propagation follows the I-II mixed type.

(2) When the prefabricated crack is on the central axis, the crack expands along the central axis after being impacted. When the prefabricated crack deviates from the central axis and moves upwards, the crack's propagation trajectory is first a circular arc, and then moves horizontally when approaching the central axis, but will not cross the central axis.

(3) When the crack is on the central axis, the displacement of the crack in the $\mathrm{X}$ direction is the largest. When the prefabricated crack is $5 \mathrm{~mm}$ away from the central axis, the energy accumulation stage has the shortest time and the initial crack initiation toughness is the lowest. When the prefabricated crack is at the edge of the roadway, the peak crack growth velocity Vzmax is the largest. As the prefabricated crack shifts upward, the displacement of the crack in the $\mathrm{Y}$ direction increases.

(4) The ABAQUS extended finite element method can better predict the crack propagation after impact when the semicircular arch roadway contains prefabricated cracks. The simulation results are basically similar to the test results.

\section{Conflicts of interest}

There are no conflicts to declare.

\section{Acknowledgments}


This work is financed by the State Key Development Program for Basic Research of China (2016YFC0600903) and the National Natural Science Foundation of China 5(1774287).

\section{References}

1 R. S. Yang, Y. B. Wang, L. D. Hou, et al, Chinese Journal of Rock Mechanics and Engineering., 2014, 33, 10.

2 Z. W. Yue, R. S. Yang, Z. H. Sun, et al, Journal of China coal society., 2010, 35, 9.

3 Y. B. Wang, R. S. Yang, G. F. Zhao, Polymer Testing., 2017, 58, 70.

4 S. C. Li, L. Yang, M. T. Li , et al, Chinese Journal of Rock Mechanics and E ngineering., 2009, 28, 2.

5 W. Liu, X. F. Yao, R. S. Yang, et al, Optics and Lasers in Engineering,. 2020, 124, 105849

6 X. F. Yao, G. C. Jin, Arakawa K, Takahashi K, Polymer Test,. 2002, $21,8$.

7 X. F. Yao, W. Xu , M. Q. Xu , Arakawa K, Mada T, Takahashi K, Polymer Test., 2003, 22, 6 .

8 De Frutos, J ; Novo, J, SIAM JOURNAL ON NUMERICAL ANALYSIS., 2002, 40, 3.

9 L. N. Y. Wong, H. Li, International Journal of solids and structures., 2013, 50, 22.

10 Moes, N, Dolbow, J, Belytschko, International Journal for Numerical Methods in Engineering., 1999, 46, 131.

11 R. L McNearny,J. ABELJR, International Journal of Rock Mechanics and Mining Sciences., 1993, 30, 93.

12 Lemnitzer,Anne, Keykhosropour,Lohrasb, Kawamata,Yohsuke, Earthquake Spectra., 2017, 33, 1 .

13 Tsinidis G, Pitilakis K, Madabhushi G, Engineering structure., 2016, 125, 419.

14 J. Fan, L. Yang, International journal of Impact Engineering., 2017, 106, 217.

15 Z. M. Zhu, B. Mohanty, H. Xie, International Journal of Rock Mechanics and Mining Sciences., 2007, 44, 3.

16 Z. M. Zhu, H. Xie, B. Mohanty, International Journal of Rock Mechanics and Mining Sciences., 2008, 45, 2.

17 X. Li, T. Zhou, D. Li, Rock mechanics and rock engineering., 2017, 50, 1.

18 F. Huang, H. Zhu, Q. Xu, et al, Tunnelling and Underground Space Technology., 2013, 35, 207.

19 Q. Yu, C. Tang, L. Li, G. Cheng, et al, Shock and Vibration., 2015, 1, 1.

20 D. M. Guo,K. Liu, J. X. Hu, et al, Journal of China Coal Society., 2016, 41, 1.

21 D. M. Guo,K. Liu, R. S. Yang, et al, Journal of Mining and Safety Engineering., 2015, 32, 1 .

22 L. Zhou, Z. M. Zhu, Y. Q. Dong, et al, Tunnelling and Underground Space Technology., 2019, 84, 11.

23 L. Zhou, Z. M. Zhu, Y. Q. Dong, et al, International Journal of Impact Engineering., 2019, 125, 134. 
24 L. Zhou, Z. M. Zhu, Y. Q. Dong, et al, Theoretical and Applied Fracture Mechanics., 2020, 109, 102733.

25 R. Goseki, Ishizone T. Poly (methyl methacrylate)(PMMA). 2015.

26 P. Manogg. Anwendung der Schattenoptik zur Untersuchung des Zerreissvorgangs von Platten (West Germany:University of Freiburg 1964).

27 Theocarism.P.S, Applied Optics., 1972, 10, 240.

28 Kalthoff ,J.F, Winkler,S. and Beinert,J, International Journal of Fracture., 1976, 12, 317.

29 D. C. Guan, Z. H. Yang, Journal of Beijing University of Technology., 1983, 3, 65.

30 X. Wu, H. T. Yang, Journal of Solid Mechanics., 1984, 2, 299.

31 L. Y. Yang, R. S. Yang, P. Xu , Journal of China University of Mining dechnology ., 2013, 2, 31 .

32 R. S. Yang, P. Xu, Z. W.Yue, Engineering Fracture Mechanics., 2016, 161, 63.

33 Y. B. Wang, R. S. Yang, G. F. Zhao, Polymer Testing., 2017, 58, 70.

34 Kalthoff, J.F, Proceedings of the Intern-ational Symposium on Photoelasticity., 198 6, 9, 109 .

35 T. Karimzada , H. Maigre Journal De Physique IV 1997,. 2000, 2, 13.

36 J.C.L, N.N.Li, H.B.Li, et al. International Journal of Impact Engineering., 2017, 105, 109. 


\section{Figures}

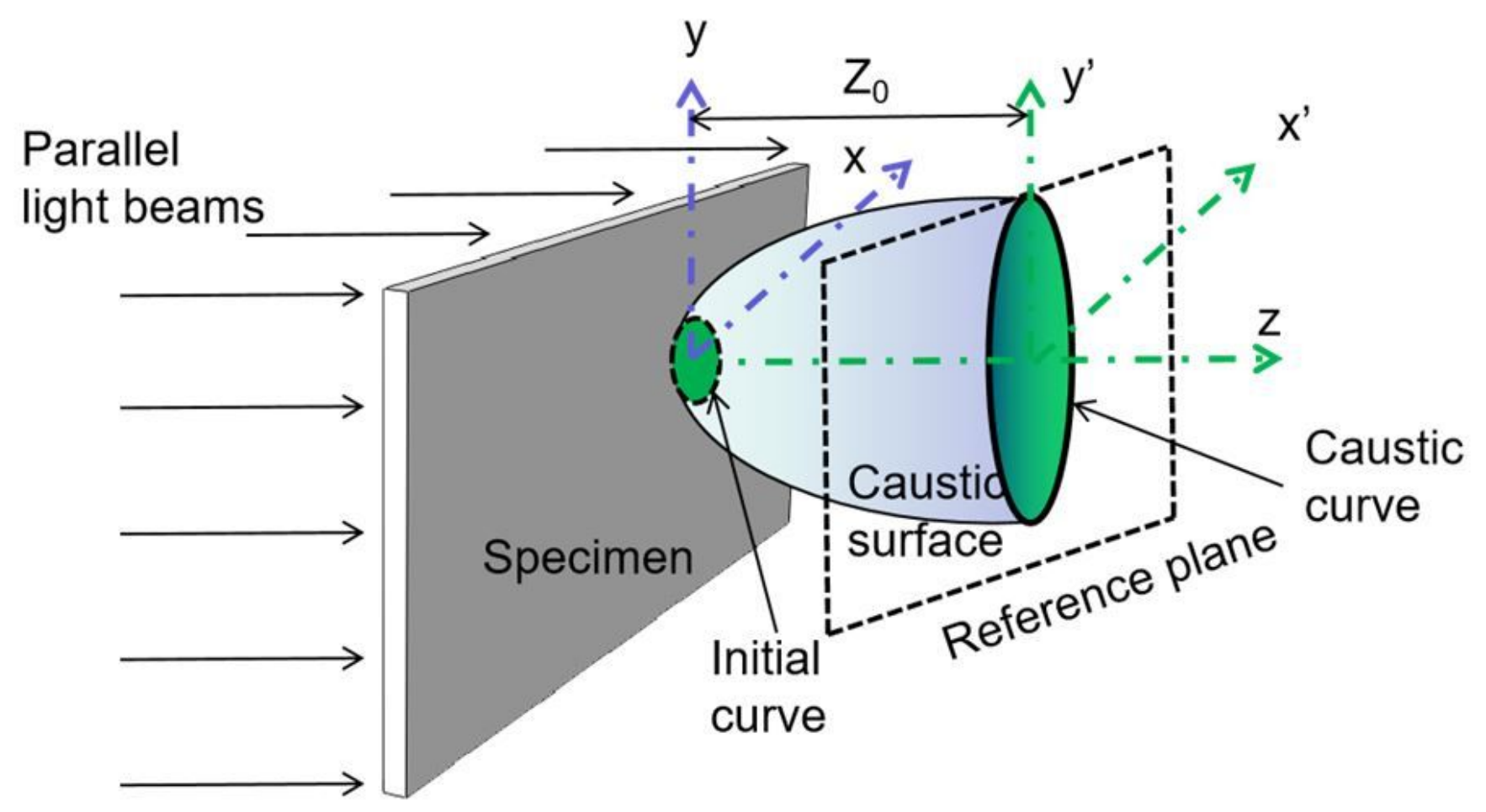

Figure 1

Caustic principle

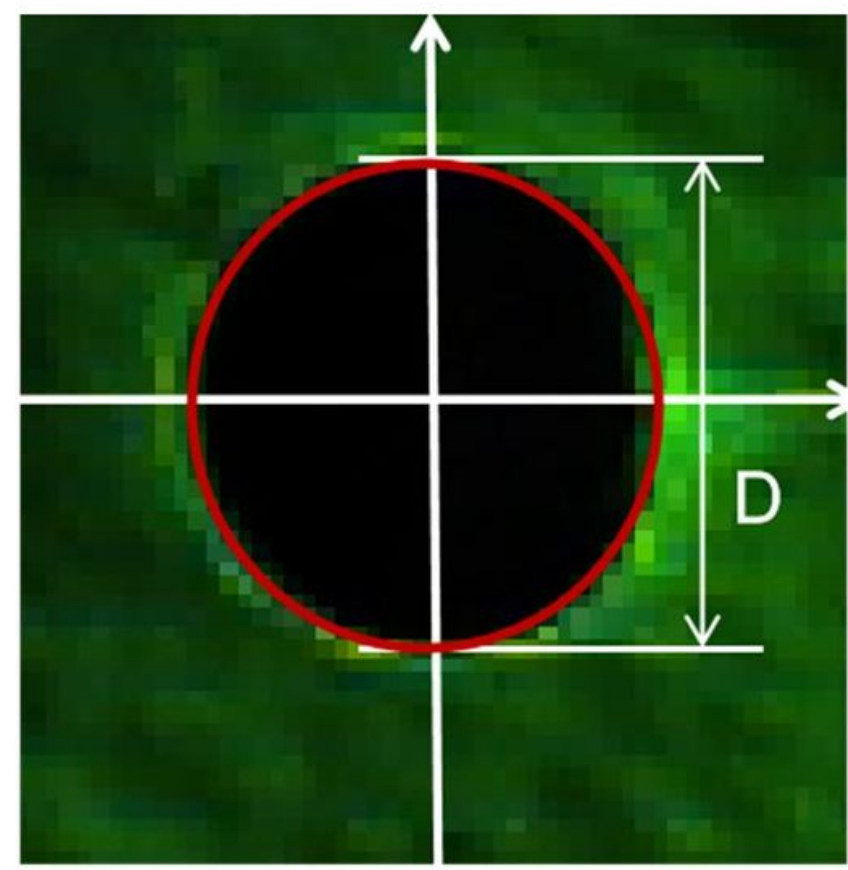

(a) mode I caustic spots

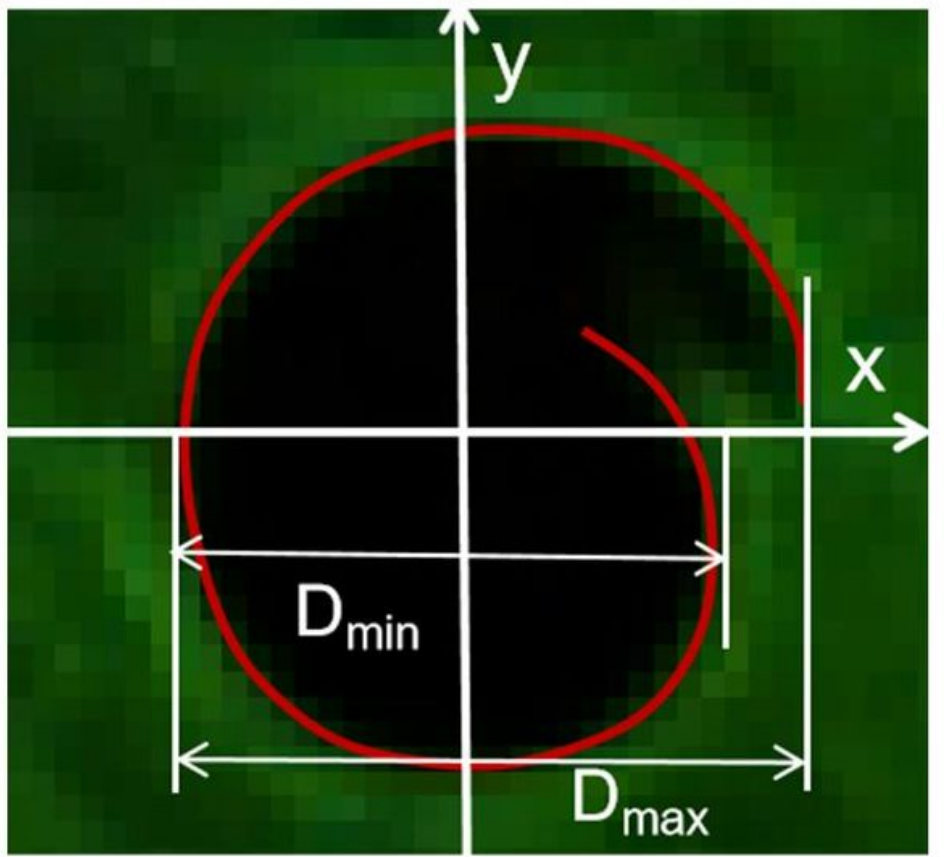

b) mixed mode I-II caustic spots 
Figure 2

Two kinds of caustic images

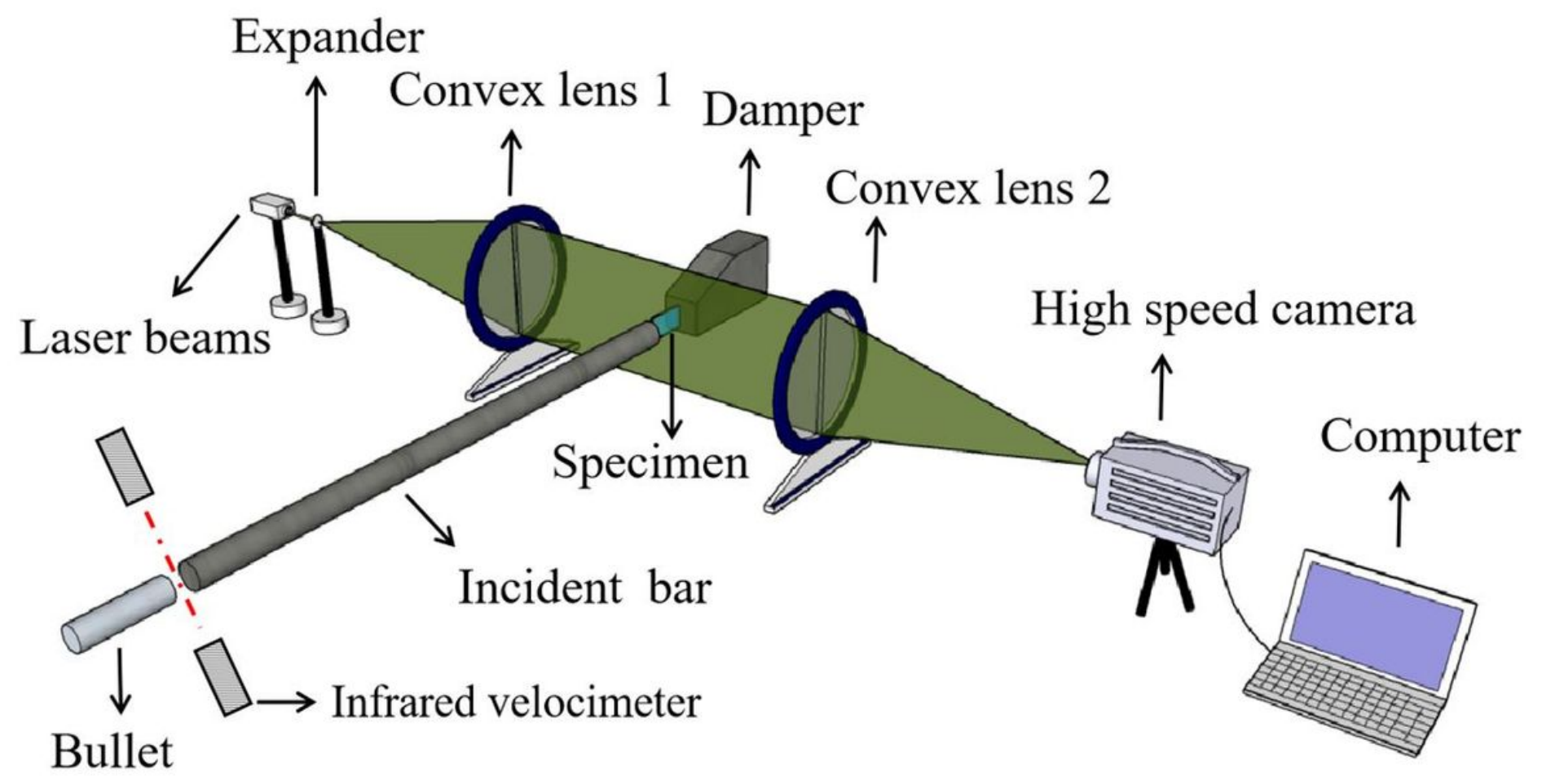

Figure 3

Testing system

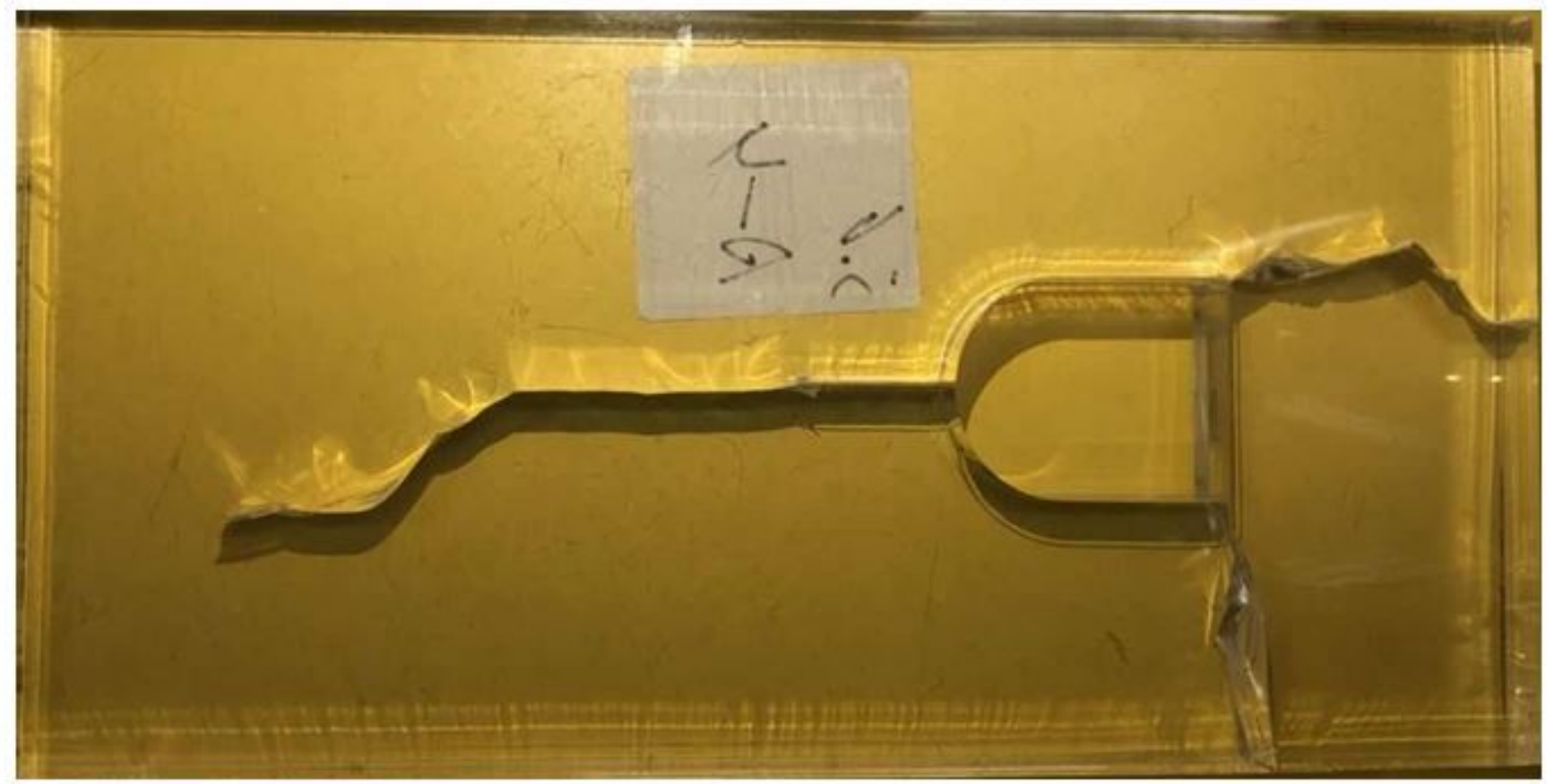


Figure 4

An abnormal failure caused by friction

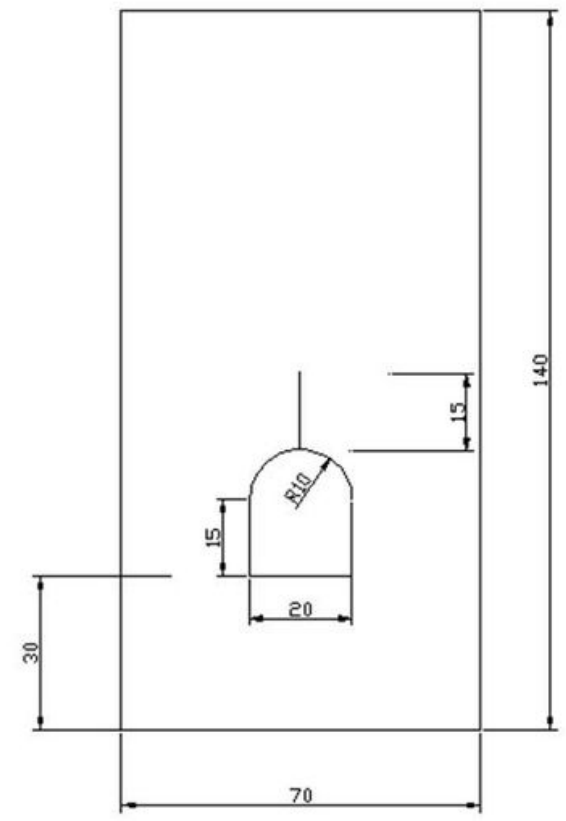

Specimen A

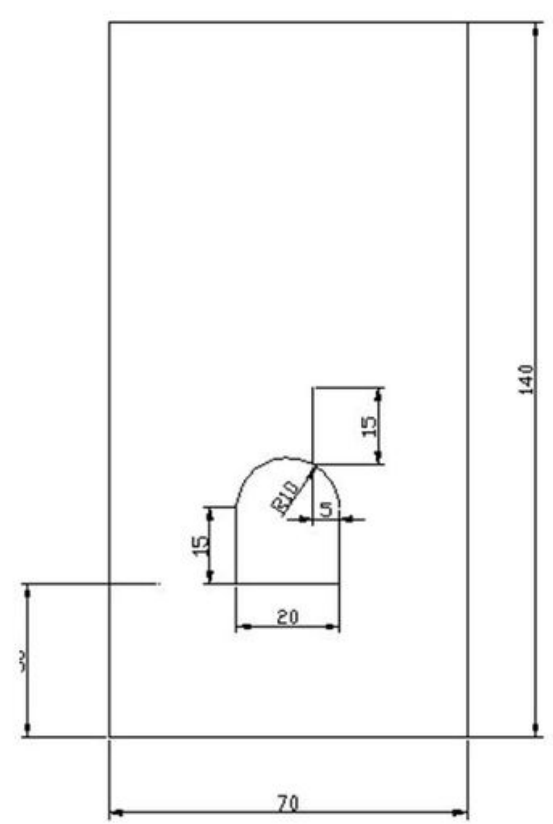

Specimen B

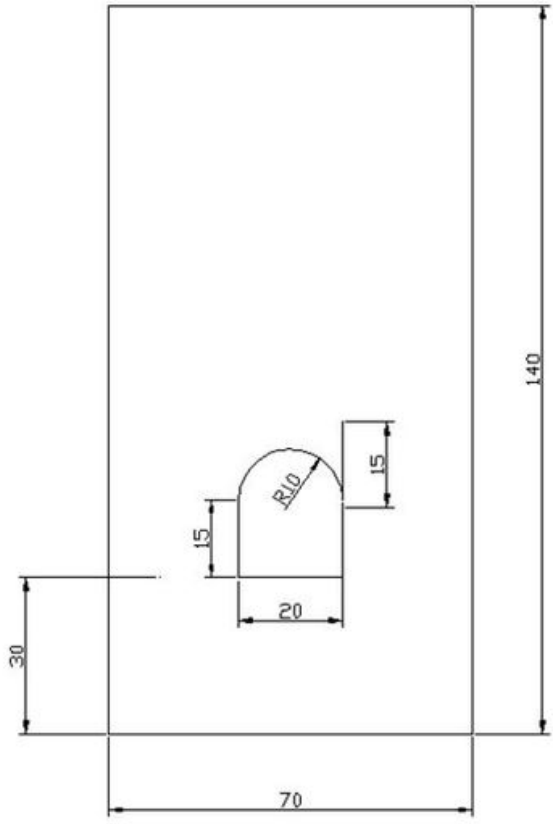

Specimen C

Figure 5

Specimen geometry

Observation area Initial notch

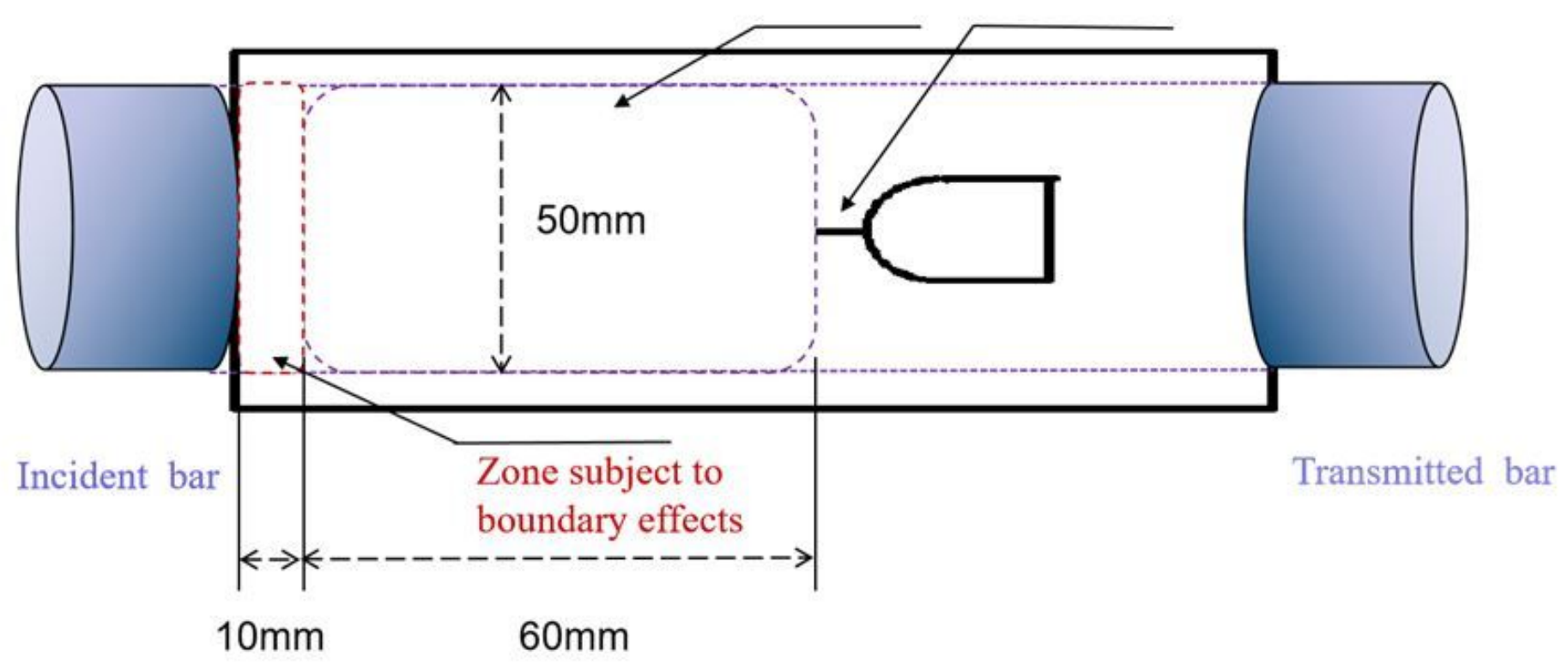

Figure 6 


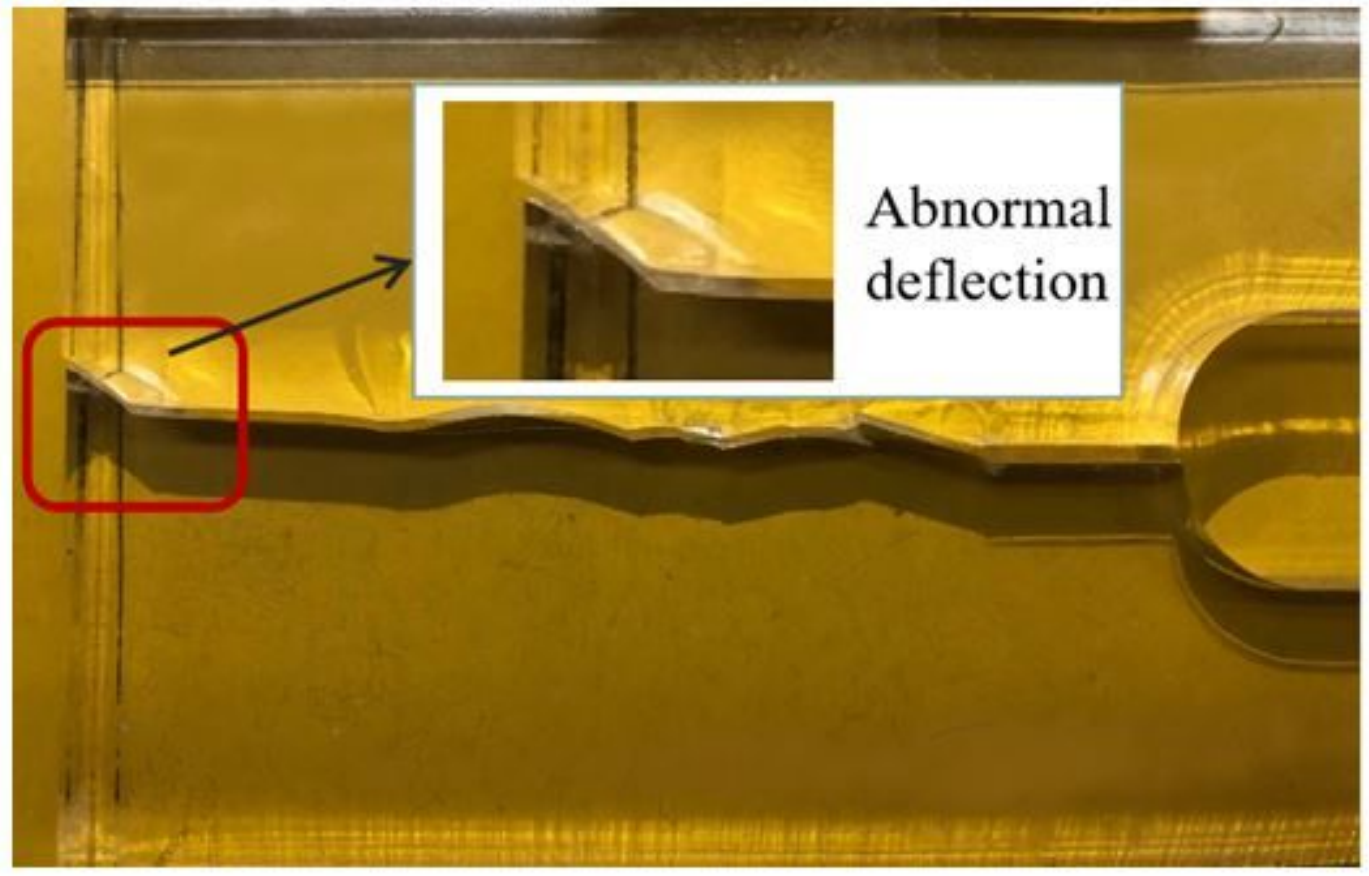

Figure 7

Subject to boundary effects

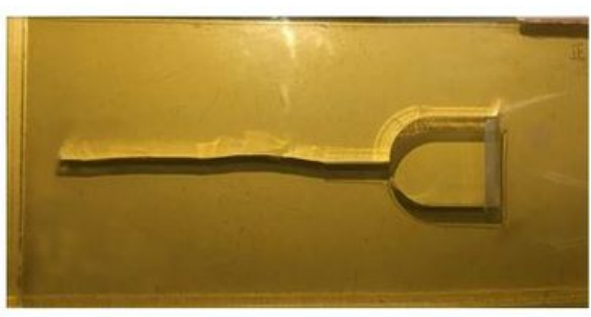

(a) Specimen $A$

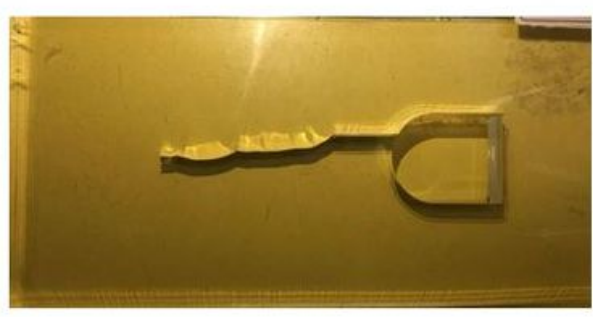

(b) Specimen B

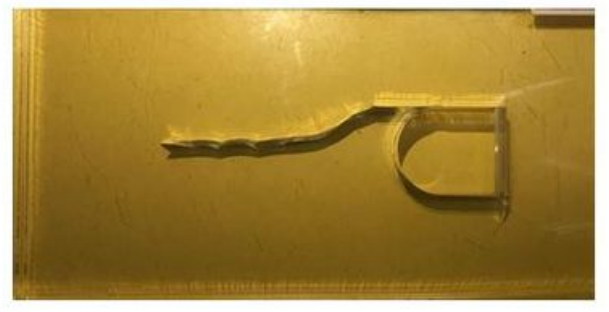

(c) Specimen C

Figure 8

Crack growth trace 

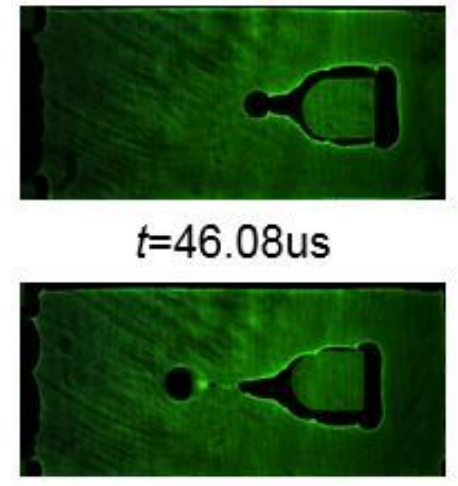

$t=1520.73$ us

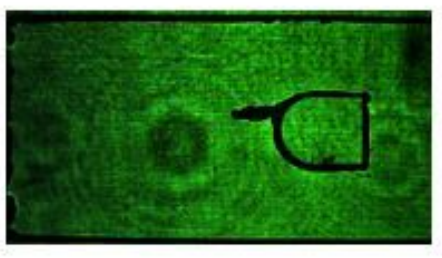

$t=13.33$ us

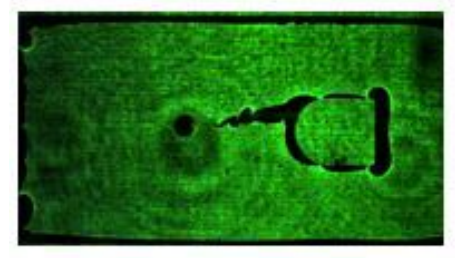

$t=973.33$ us

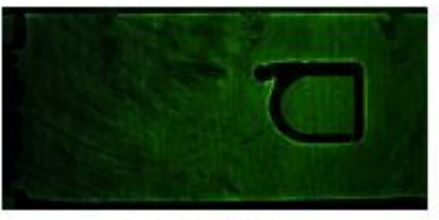

$t=15.36$ us

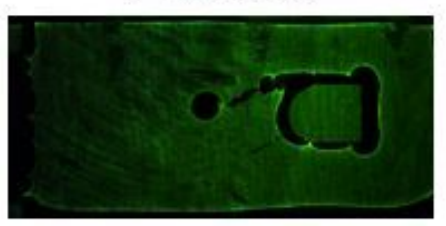

$t=1182.79$ us
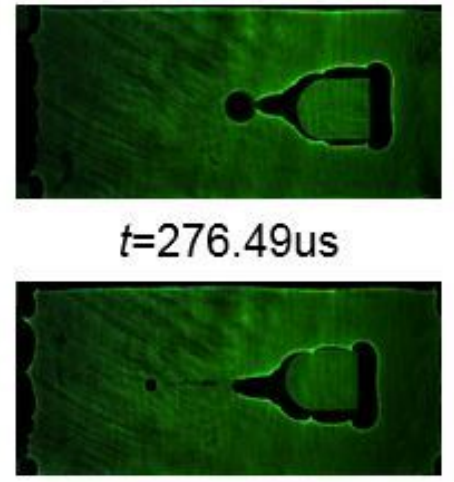

$t=2457.75$ us

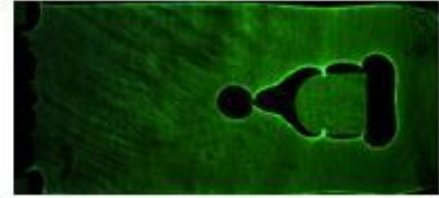

$t=829.49$ us

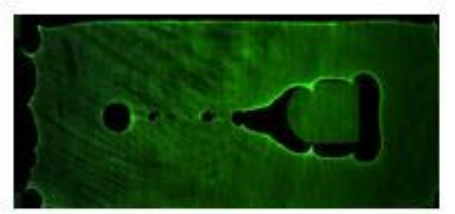

$t=2749.61$ us

(a) Specimen $A$

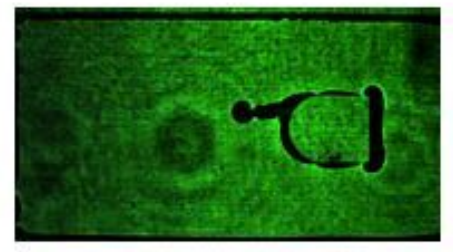

$t=93.33$ us

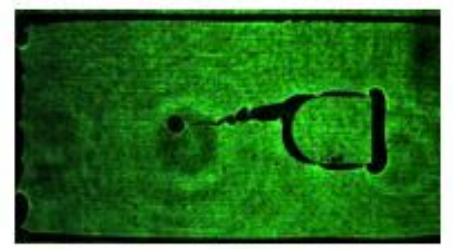

$t=1213.33$ us

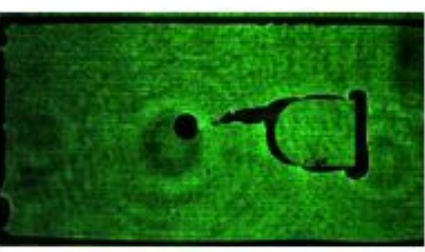

$t=466.66$ us

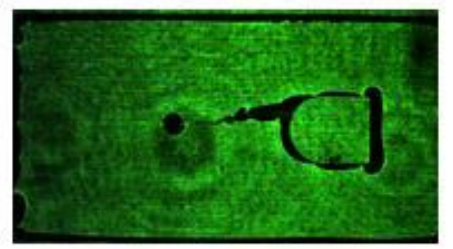

$t=1466.66$ us

(b) Specimen B

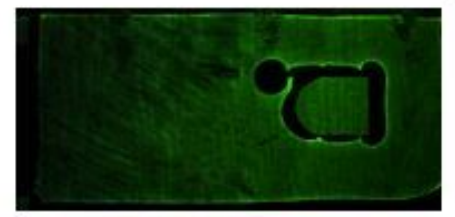

$$
t=138.24 \text { us }
$$

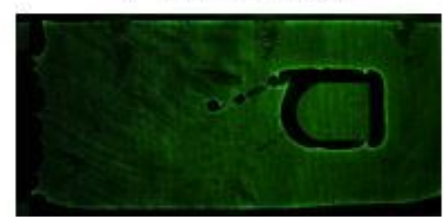

$t=1290.32$ us

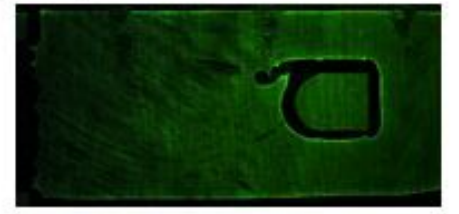

$t=691.24$ us

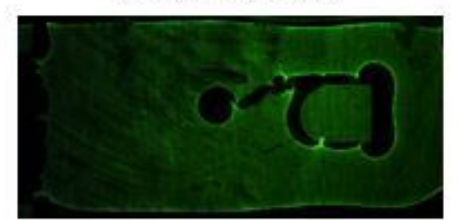

$t=1643.62$ us

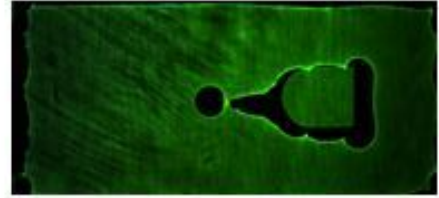

$t=1182.79$ us

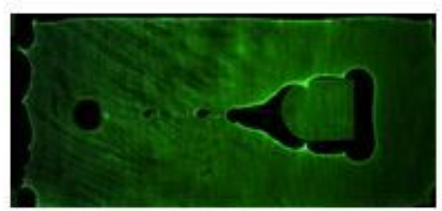

$t=2903.22$ us

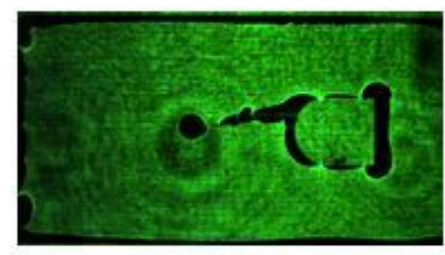

$t=920$ us

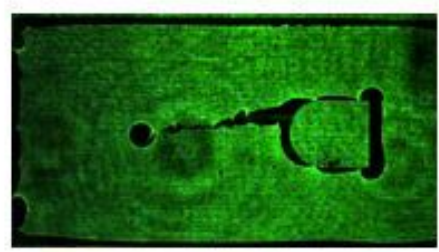

$t=1840$ us

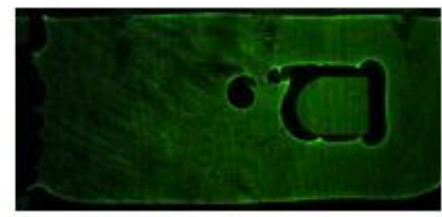

$t=921.65$ us

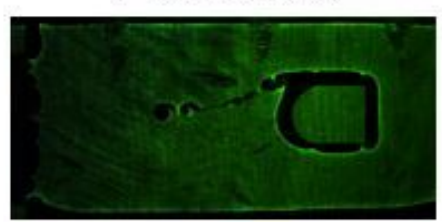

$t=2319.5$ us

(c) Specimen $C$

Figure 9

Dynamic caustic image patterns at crack in specimens under different locations of prefabricated cracks 


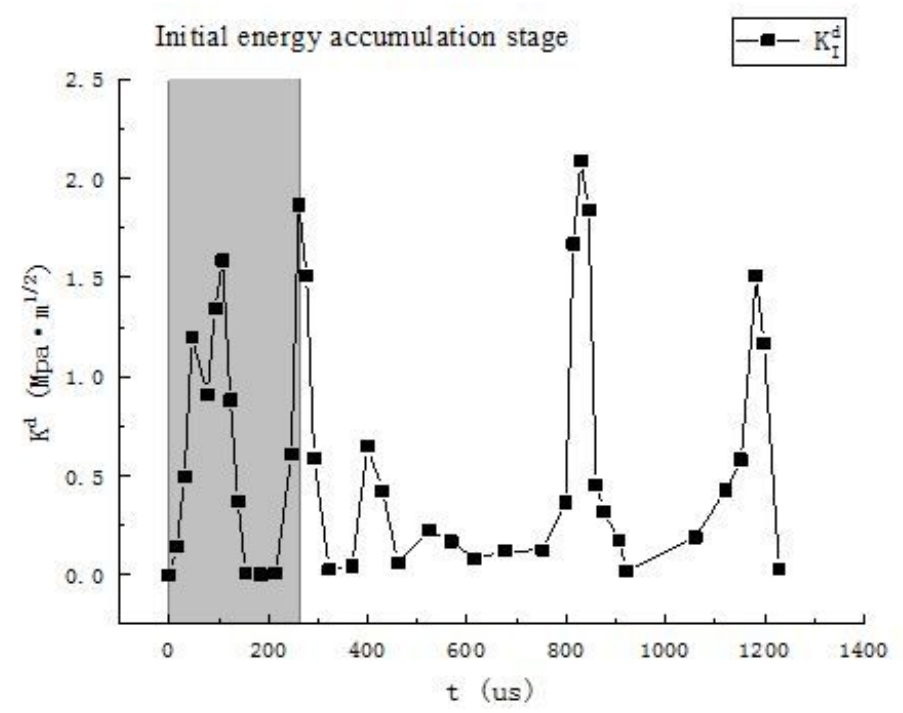

(a) Specimen A

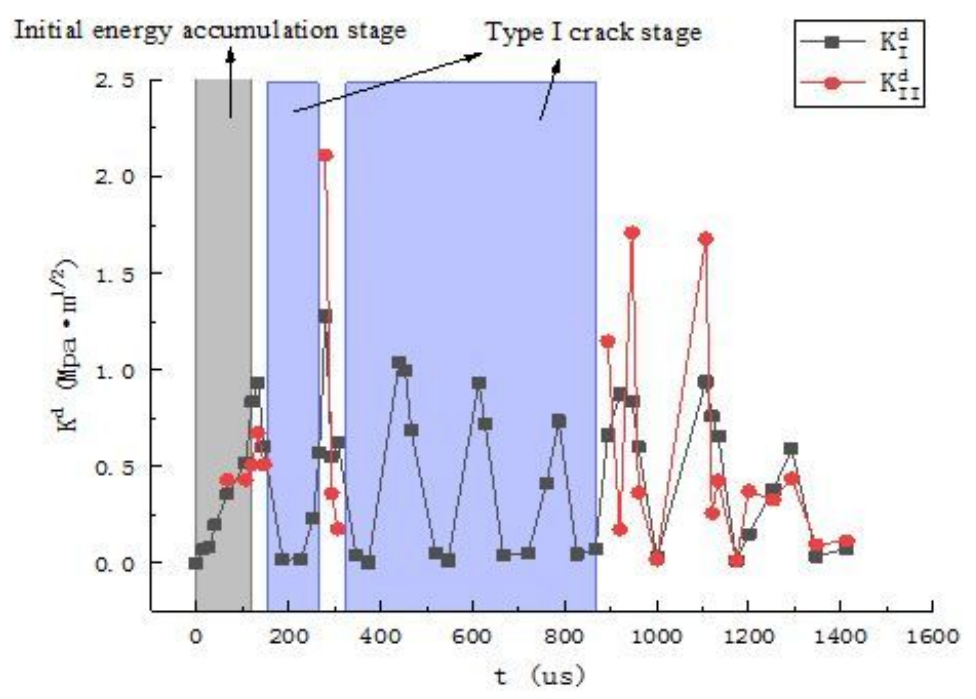

b) Specimen B

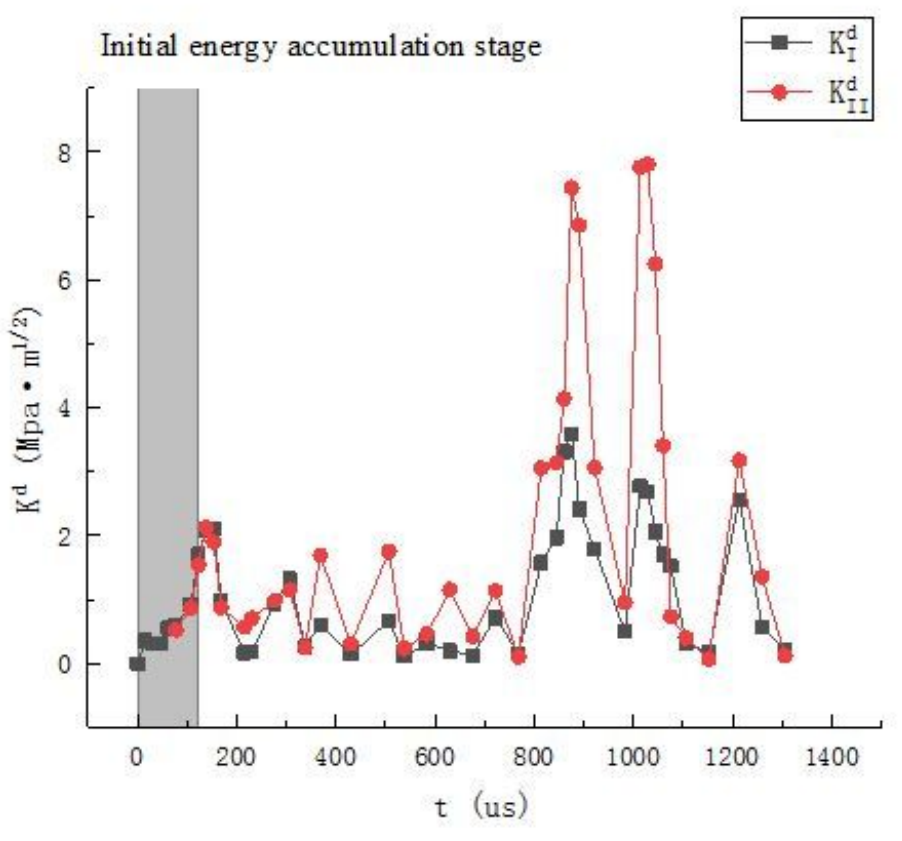

(c) Specimen C

Figure 10

The DSIF-time curve under different specimen 


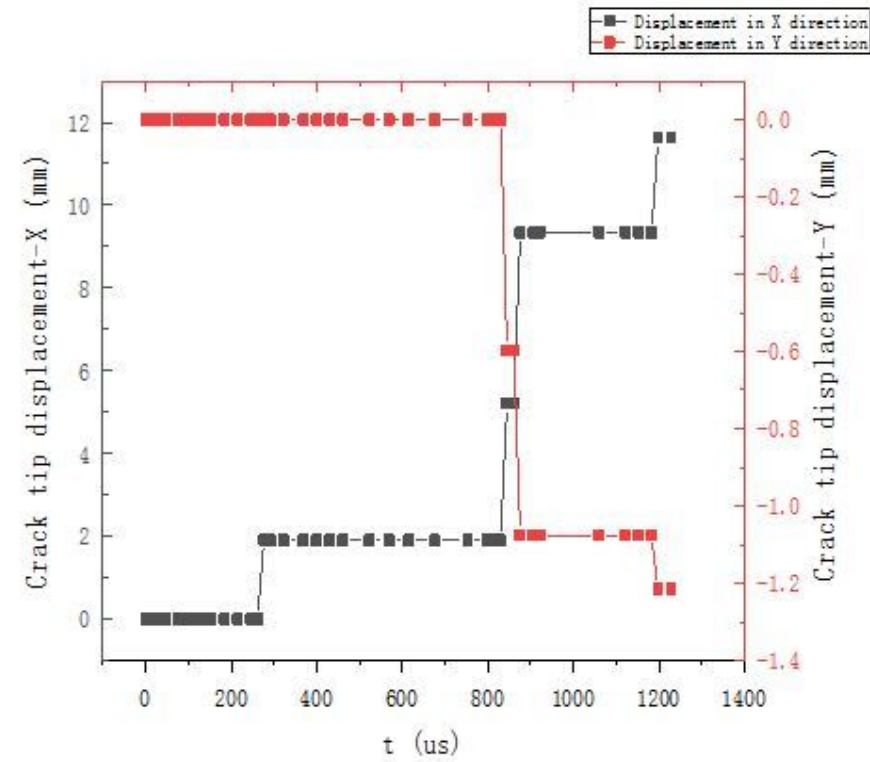

(a) Specimen A

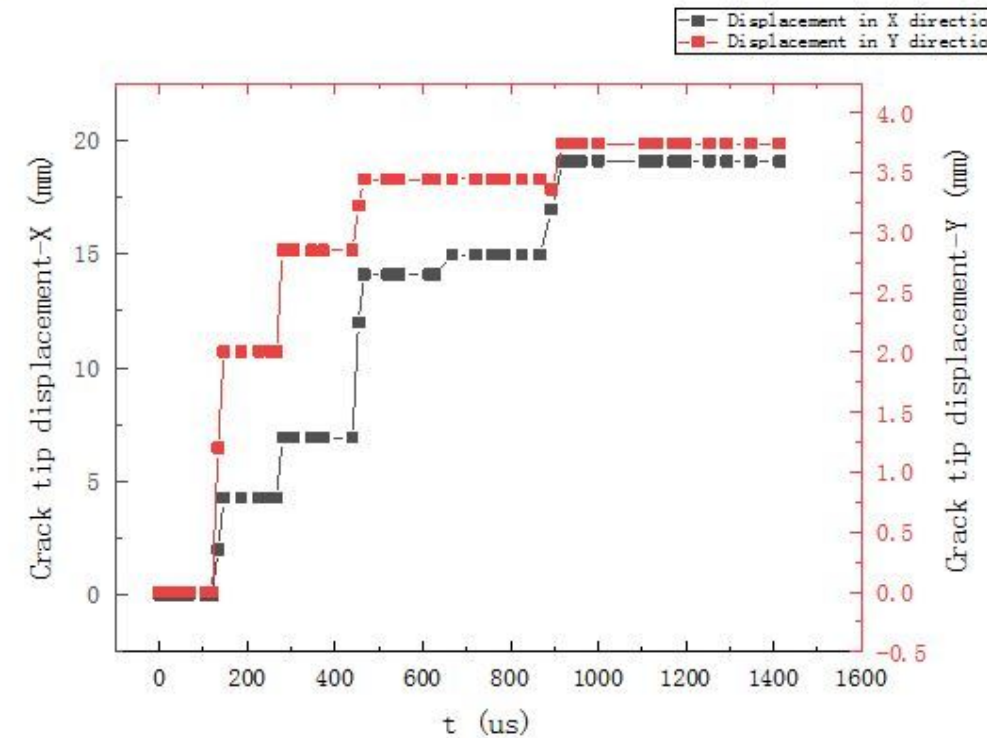

b) Specimen B

\section{- Displacement in $\mathrm{X}$ dirsection}

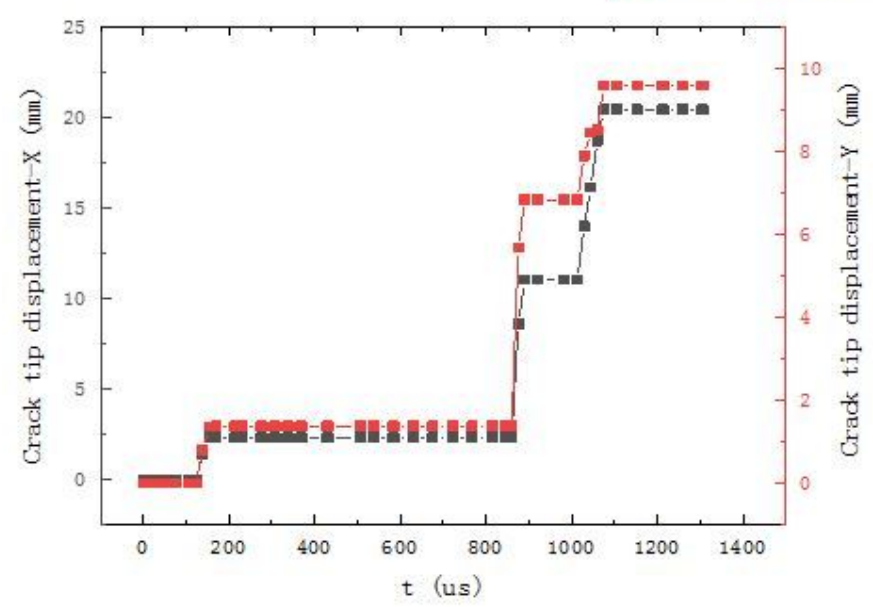

(c) Specimen C

\section{Figure 11}

Crack tip propagation time history curve 


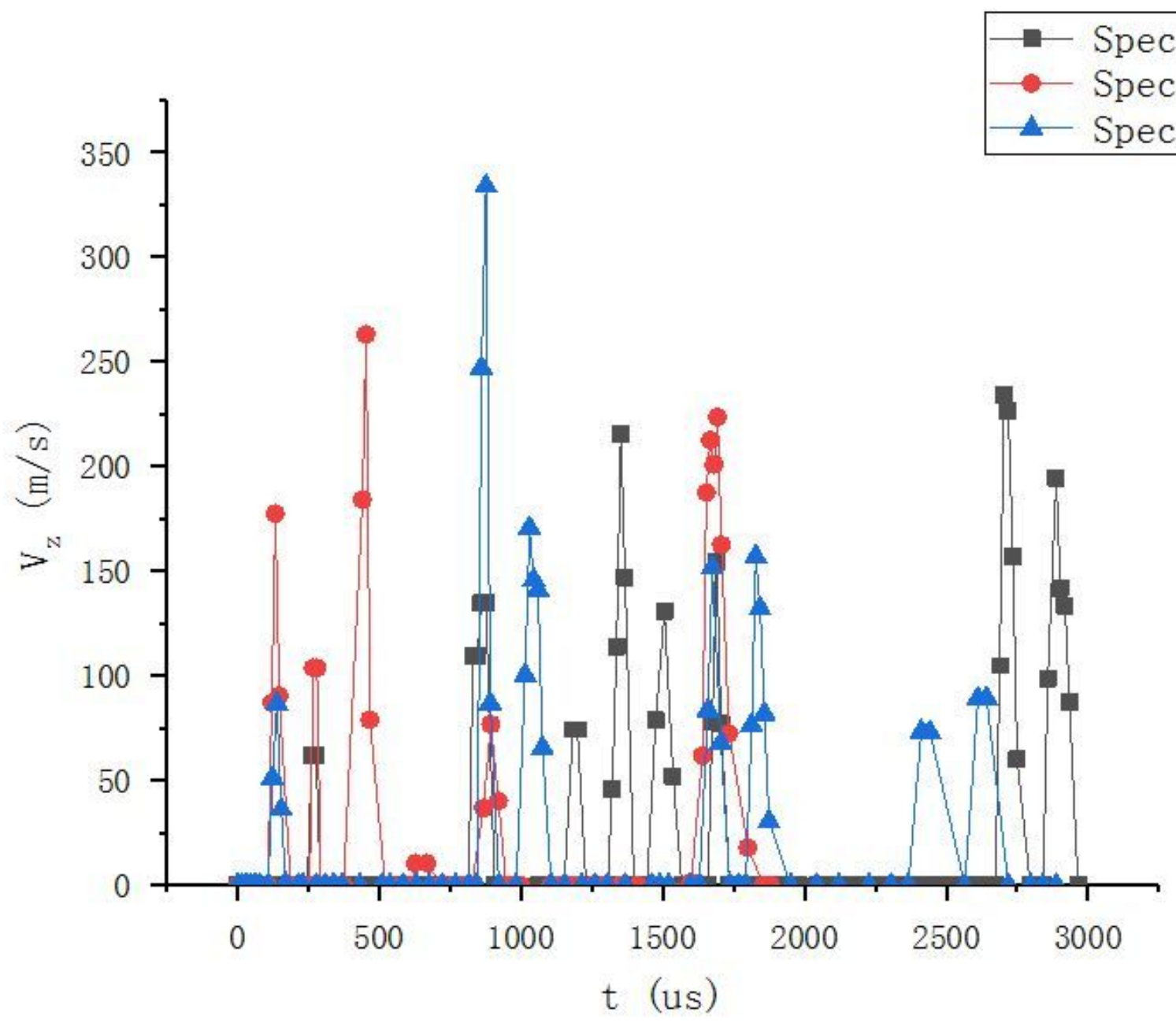

Figure 12

The Vz velocity of crack growth varies with time 


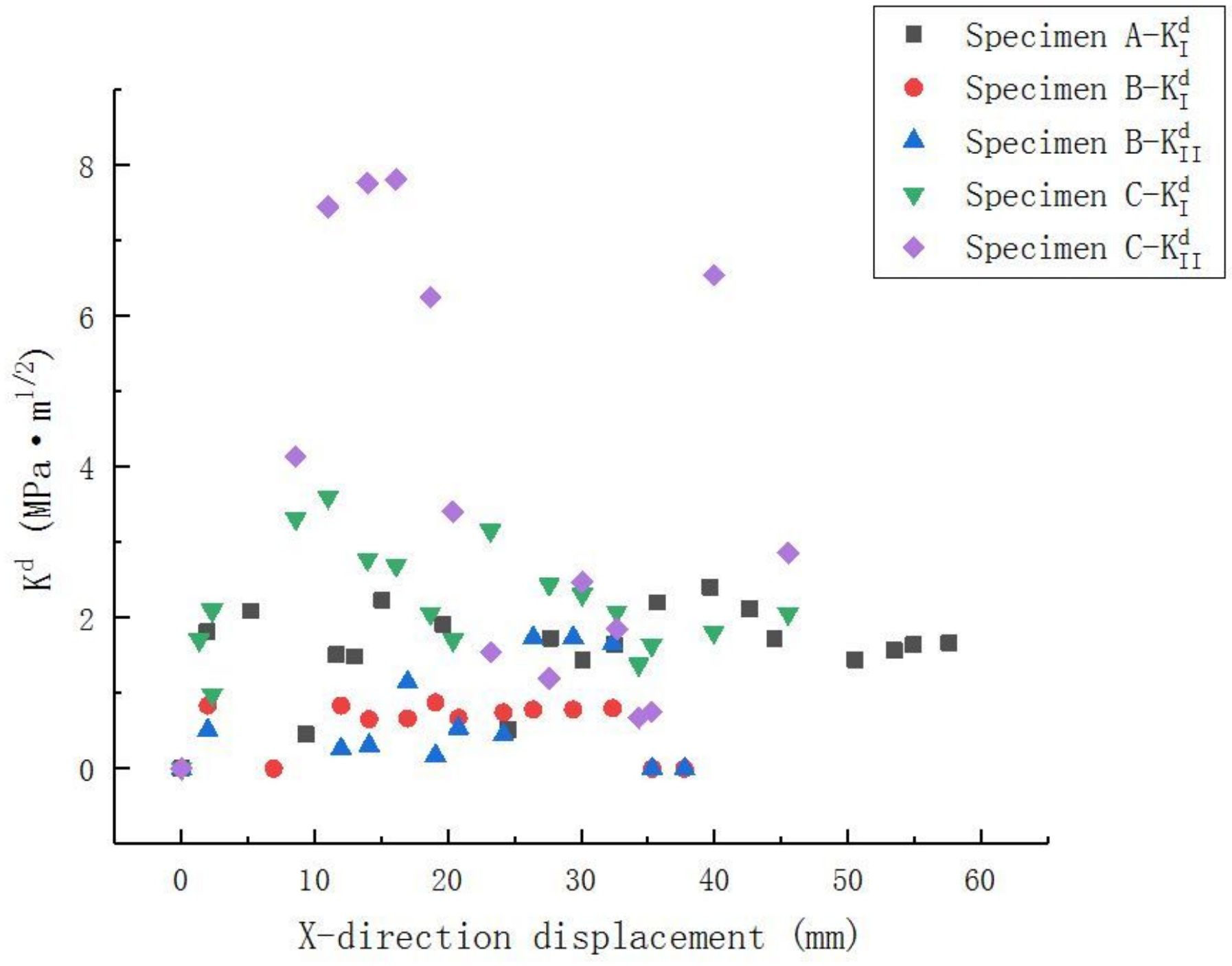

Figure 13

Crack propagation DSIF varies with displacement in X direction

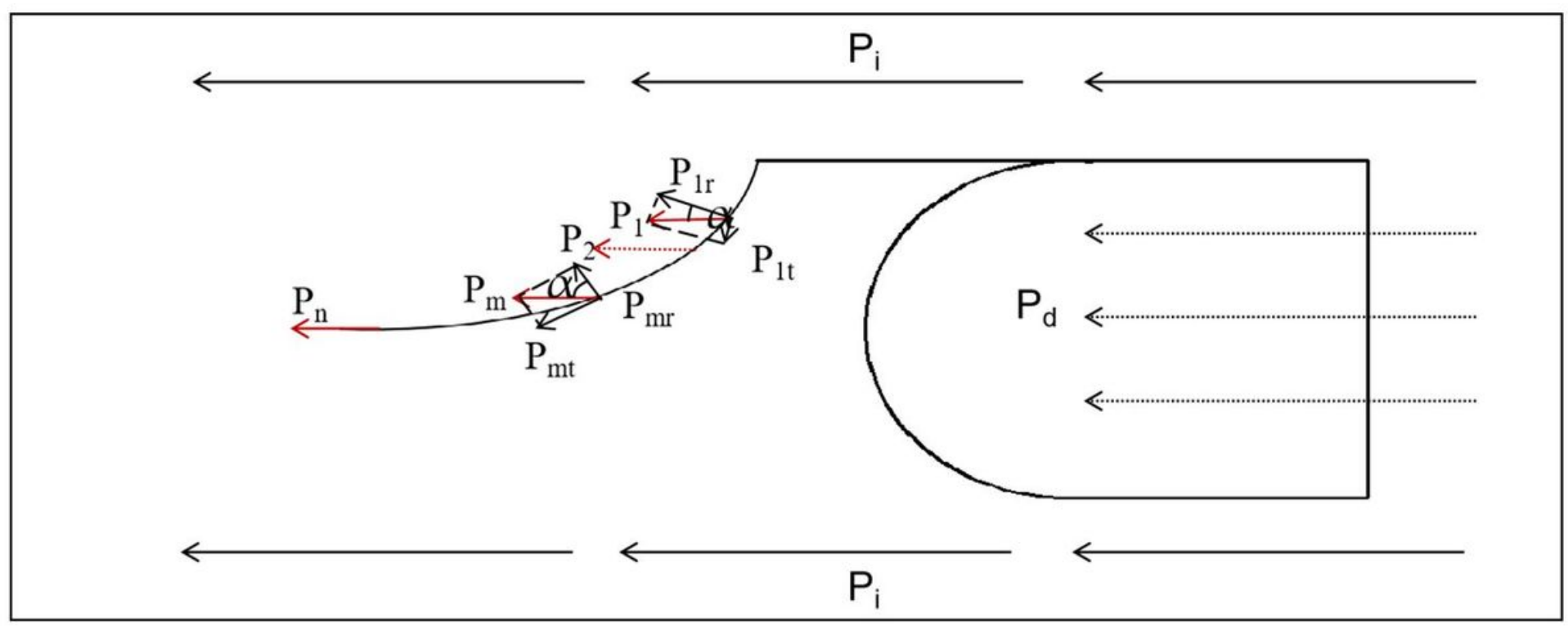


Figure 14

Effect of stress wave on crack

\section{Figure 15}

Case of a meshed output bar

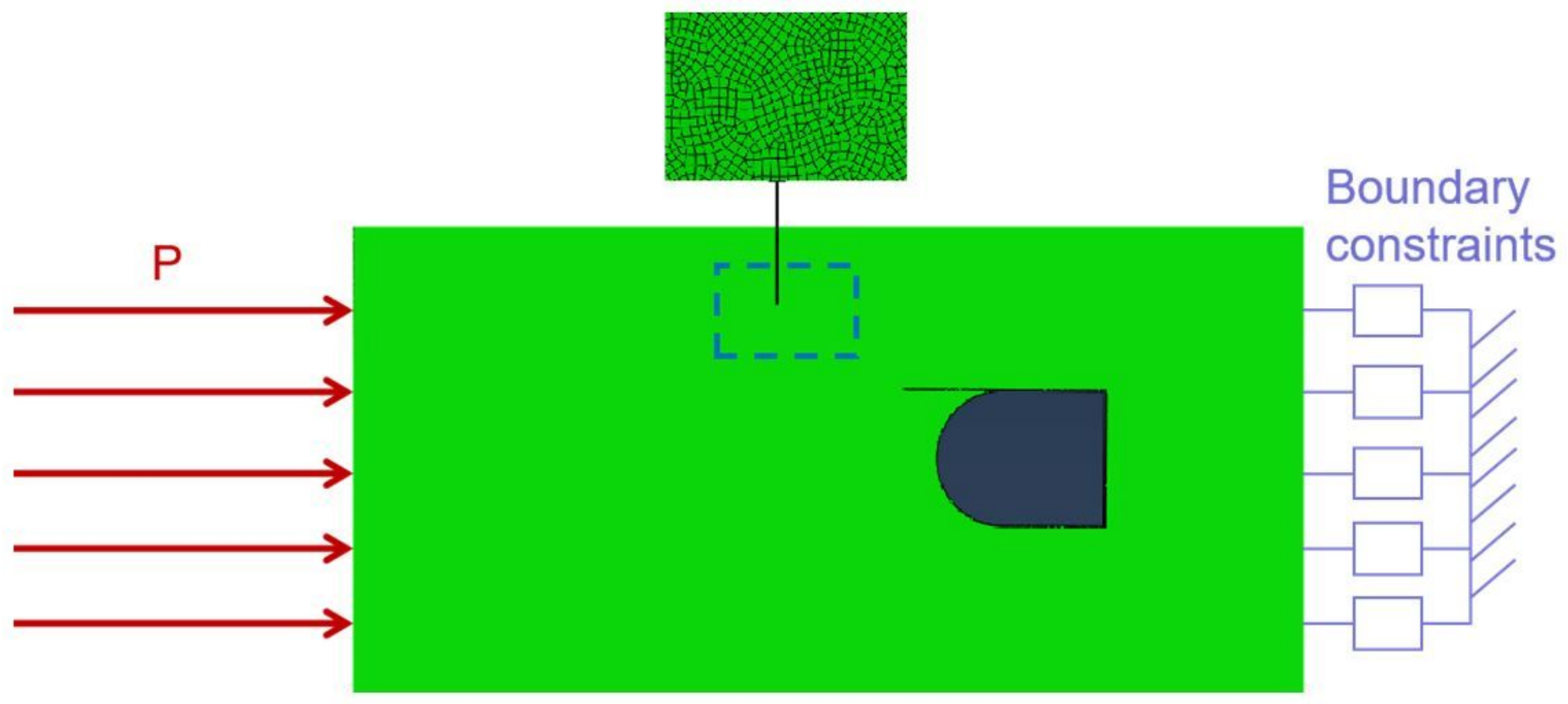

Figure 16

Typical mesh in ABAQUS

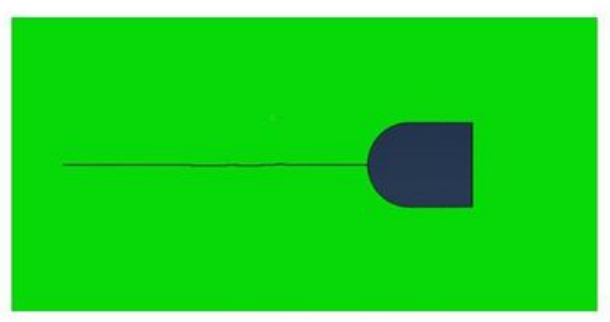

Specimen A

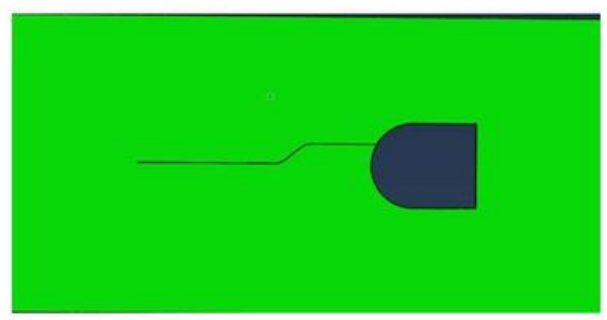

(b) Specimen B

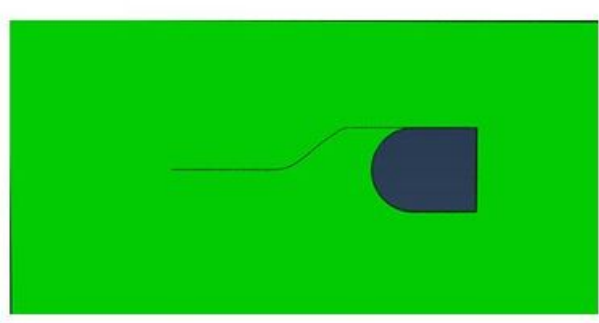

(c) Specimen C

\section{Figure 17}

Simulation of crack propagation for three types of specimens under 


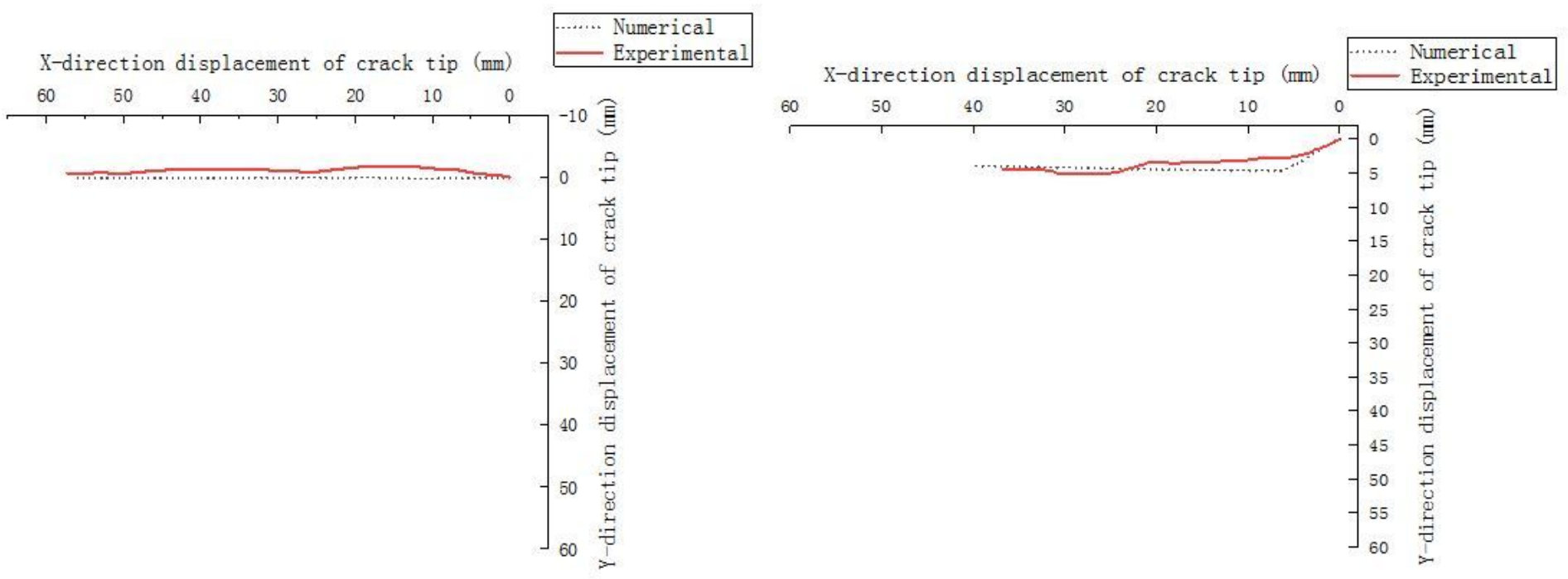

(a) Specimen $A$

(b) Specimen B

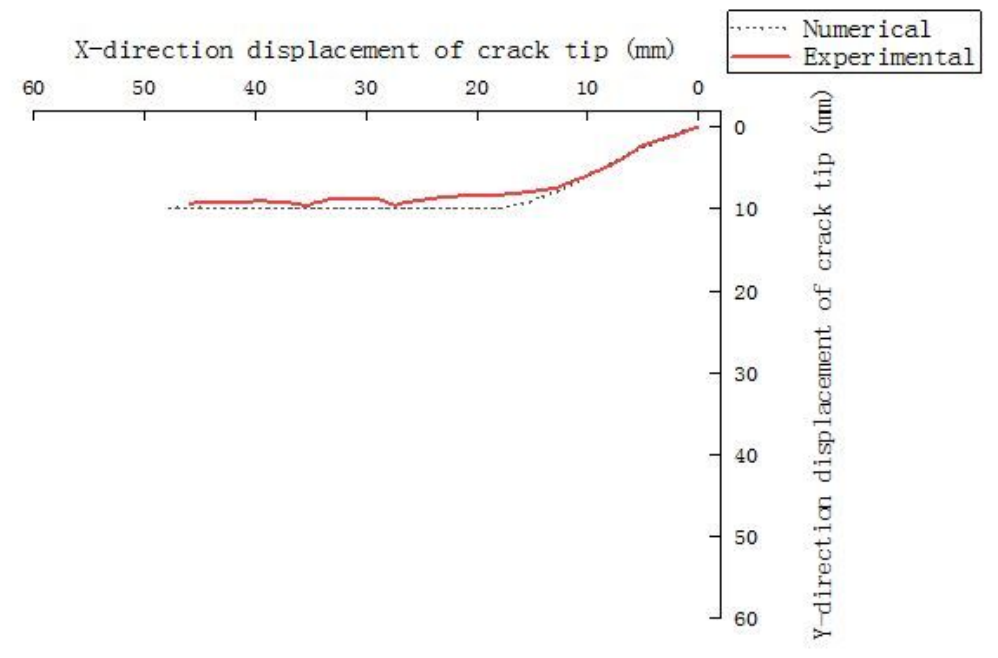

(c) Specimen C

Figure 18

Comparison of crack paths 